\title{
A new specimen of Sinopterus dongi (Pterosauria, Tapejaridae) from the Jiufotang Formation (Early Cretaceous, China)
}

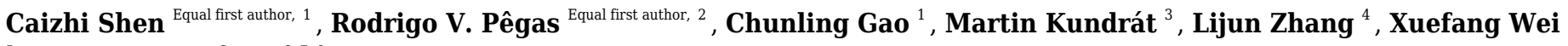 \\ 5 , Xuanyu Zhou Corresp. 6, 7,8 \\ ${ }^{1}$ Dalian Natural History Museum, Dalian, Liaoning, China \\ 2 Laboratório de Paleontologia de Vertebrados e Comportamento Animal, Federal University of ABC, São Paulo, Brazil \\ 3 Evolutionary Biodiversity Research Group, PaleoBiolmaging Lab, Center for Interdisciplinary Biosciences, Technology and Innovation Park, \\ Pavol Jozef Safárik University, Kosice, Slovak Republic \\ 4 Hainan Tropical Ocean University, Sanya, Hainan, China \\ 5 Institute of Geology, Chinese Academy of Geological Sciences, Beijing, China \\ 6 School of Sciences, Hokkaido University, Sapporo, Japan \\ 7 Hokkaido University Museum, Hokkaido University, Sapporo, Japan \\ 8 Beipiao Pterosaur Museum of China, Beipiao, Liaoning, China \\ Corresponding Author: Xuanyu Zhou \\ Email address: xyzhou@elms.hokudai.ac.jp
}

The Tapejarinae are edentulous pterosaurs that are relatively common in Cretaceous continental deposits in South America, North Africa, Europe, and China (mostly Early Cretaceous). The Chinese jiufotang Formation is particularly rich in tapejarine specimens, having yielded over 10 described specimens and dozens of undescribed ones. For the jiufotang Formation, a total of 7 nominal tapejarid species and 2 genera have been proposed. Some debate exists over how many of those are valid or, alternatively, sexual or ontogenetic morphs of fewer (or even a single) species. Despite the abundance of specimens and the relevant taxonomic problems involved, detailed revisions of the matter are still lacking. This is partly due to the relatively scarce knowledge on the comparative osteology of the Sinopterus complex, which is hampered by the fact that most specimens have been only preliminarily described. In this contribution, we present a new postcranial specimen, D3072, which we attribute to the type-species of the genus, Sinopterus dongi. This new specimen helps shed some new light in the osteology of Sinopterus dongi, hopefully serving as a basis for future comparative studies involving further specimens and other proposed species and, subsequently, taxonomic revisions. 


\section{A new specimen of Sinopterus dongi (Pterosauria,}

2 Tapejaridae) from the Jiufotang Formation (Early

\section{Cretaceous, China)}

4 Caizhi Shen ${ }^{1 \dagger}$, Rodrigo V. Pêgas ${ }^{2 \dagger}$, Chualing Gao ${ }^{1}$, Martin Kundrát ${ }^{3}$, Lijun Zhang ${ }^{4}$, Xuefang

5 Wei ${ }^{5}$, Xuanyu Zhou ${ }^{6,7,8^{*}}$

6

7 1. Dalian Natural History Museum, Dalian, Liaoning, China.

8 2. Federal University of $\mathrm{ABC}$, São Bernardo, Brazil.

9 3. Evolutionary Biodiversity Research Group, PaleoBioImaging Lab, Center for Interdisciplinary

10 Biosciences, Technology and Innovation Park, Pavol Jozef Safárik University, Kosice, Slovak

11 Republic.

12 4. Hainan Tropical Ocean University, Sanya, Hainan, China.

13 5. Institute of Geology, Chinese Academy of Geological Sciences, Beijing, China.

14 6. School of Sciences, Hokkaido University, Sapporo, Japan.

7. Hokkaido University Museum, Hokkaido University, Sapporo, Japan.

8. Beipiao Pterosaur Museum of China, Beipiao, Liaoning, China.

Corresponding Author:

Xuanyu Zhou

Hokkaido University, Sapporo, Japan

Email address: xyzhou@elms.hokudai.ac.jp

${ }^{\dagger}$ These authors contributed equally to this work

\section{Abstract}

The Tapejarinae are edentulous pterosaurs that are relatively common in Cretaceous continental deposits in South America, North Africa, Europe, and China (mostly Early Cretaceous). The Chinese Jiufotang Formation is particularly rich in tapejarine specimens, having yielded over 10 described specimens and dozens of undescribed ones. For the Jiufotang Formation, a total of 7 
32 of those are valid or, alternatively, sexual or ontogenetic morphs of fewer (or even a single) 33 species. Despite the abundance of specimens and the relevant taxonomic problems involved, detailed revisions of the matter are still lacking. This is partly due to the relatively scarce knowledge on the comparative osteology of the Sinopterus complex, which is hampered by the fact that most specimens have been only preliminarily described. In this contribution, we present a new postcranial specimen, D3072, which we attribute to the type-species of the genus, Sinopterus dongi. This new specimen helps shed some new light in the osteology of Sinopterus dongi, hopefully serving as a basis for future comparative studies involving further specimens and other proposed species and, subsequently, taxonomic revisions.

\section{Introduction}

The Tapejarinae (sensu Kellner \& Campos, 2007) are a peculiar clade of Cretaceous edentulous pterosaurs of the group Azhdarchoidea (Pterodactyloidea, Eupterodactyloidea), defined as the most inclusive clade comprehending Tapejara wellnhoferi but not Thalassodromeus sethi (Kellner \& Campos, 2007). They are characterized by their short, downturned rostra and sagittal premaxillary and dentary crests that start on the rostral region of the skull (Kellner \& Campos, 2007). They comprise over 10 species (up to 19 proposed species), spanning from the Barremian to the Santonian; with records from Brazil, Morocco, Europe and China (Kellner \& Campos, 2007, Vullo et al., 2012, Andres et al., 2014, Pêgas et al., 2016, Martill et al., 2020).

In China, tapejarines are a common element of the famous Jehol Biota (e.g. Wang \& Zhou, 2006). From the Yixian Formation (late Barremian - early Aptian), a single species, represented by two specimens, has been described: Eopteranodon lii (Lü \& Zhang, 2005; Andres \& Ji, 2008; Vullo et al., 2012). It is, however, in the Jiufotang Formation (early Aptian) that a great abundance of tapejarines is found. A total of 12 Jehol tapejarine specimens have been formally reported in the literature (Wang \& Zhou, 2003a; Li et al., 2003; Lü \& Zhang, 2005; Lü \& Yuan, 2005, Lü et al., 2006a,b,c, 2007, 2016; Liu et al., 2015; Zhang et al., 2019). Under the accounts of $\mathrm{Wu}$ et al. (2017), at least further 9 undescribed specimens are currently deposited in 
Paleontological Museum of Liaoning, and further 4 in Shandong University of Science and Technology. According to our observations, further tens of specimens can be found in the collections of other institutions such as the Beipiao Pterosaur Museum of China, the Dalian Natural History Museum, and the Chaoyang National Geopark; bringing the total of recovered specimens to over a hundred. Thus, tapejarines seem to represent an important element of the Jehol Biota.

Sinopterus dongi, from the Jiufotang Formation (see Wang \& Zhou, 2003a), was the first tapejarid to be recovered from China, and is the type-species of the genus Sinopterus. Subsequently, further six tapejarid species coming from the Jiufotang Fm. have also been proposed: Sinopterus gui, Sinopterus lingyuanensis, Huaxiapterus jii, Huaxiapterus corollatus, Huaxiapterus benxiensis and Huaxiapterus atavismus (see Wang \& Zhou, 2003a; Li et al., 2003; Lü \& Yuan, 2005; Lü et al., 2006; 2007; 2016). The Jiufotang Fm. tapejarines are involved in a complex series of taxonomic controversies, with the genus Huaxiapterus widely considered as a junior synonym of Sinopterus (Wang \& Zhou, 2006; Wang \& Dong, 2008; Witton, 2013; Zhang et al., 2019; Naish et al., 2021). At the species-level, basically two taxonomic schemes presently exist for the genus Sinopterus, which could each be viewed as a conservative and an expansive one. The conservative scheme, proposed by Witton (2013) and favored by Naish et al. (2021), poses that Jiufotang tapejarines are oversplit, and that most, if not all, Jiufotang tapejarines are members of an ontogenetic continuum of a single species, Sinopterus dongi. On the other hand, the expansive scheme of Zhang et al. (2019) poses that Jiufotang tapejarines represent at least five valid species within the genus Sinopterus: $S$. dongi, S. corollatus, S. benxiensis, $S$. lingyuanensis and S. atavismus. The latter scheme derives from the scheme of Lü et al. (2016), which posed that Sinopterus (with three species) and "Huaxiapterus" (with four species) are in fact distinct at the generic level, what could thus be considered as a third scheme for the taxonomy of the Sinopterus complex (a multi-generic, and also expansive, one).

Despite the abundance of tapejarid remains known from the Jiufotang Formation - and the 
85

relevant taxonomic problems involved - not much has been published on the detailed, comparative osteology of Sinopterus. Most of the reported specimens were only preliminarily described and figured, to the exception of the recently published IVPP 22388-V, attributed to Sinopterus atavismus (Zhang et al., 2019). The detailed description of some of these specimens, such as the holotype of Sinopterus gui, is further hampered by their poor preservation (Li et al., 2003). This issue becomes particularly problematic due to the complicated taxonomic disputes involved in the Sinopterus complex, which cannot be resolved before a detailed reassessment of all known specimens.

Specimen D3072 is a newly reported specimen coming from the Jiufotang Formation, represented by an almost complete, well-preserved postcranial skeleton. Due to its limb proportions and pedal morphology, we attribute it to Sinopterus dongi, and defend such attribution under both the conservative or the expansive taxonomic schemes for Sinopterus. The main purpose of the present contribution is to offer a detailed account of the osteology of this new specimen, improving knowledge on the anatomy of Sinopterus dongi. The importance of such data lies in the need for detailed taxonomic revisions of this genus in the future, which will require a better understanding of the osteology of Sinopterus.

\section{Material \& Methods}

\section{Specimen and geological setting}

Specimen D3072 is permanently stored in the paleontological collection of the Dalian Natural History Museum, in Dalian, Liaoning, China. The specimen was analyzed first-hand and under lenses, measured with the use of calipers, and digitally photographed. Although it lacks precise data on its origin or coordinates, it is catalogued as having been privately collected in the Dapingfang locality (Dapingfang Town, Chaoyang City, Liaoning Province), in rocks belonging to the Jiufotang Formation. The Jiufotang Formation (early Aptian), together with the underlying Yixian Formation (late Barremian - early Aptian), belongs to the Jehol Group. Together (along 
111 also with the Barremian Huajiying Formation of the Sichakou-Senjitu Basin), they yield the

112 Jehol Biota, famous for its paleontological richness and exquisite fossil preservation (e.g. Pan et 113 al., 2013; Xu et al., 2020). The Dapingfang locality has yielded several other Jiufotang Fm.

114 fossils of vertebrate taxa, such as: the azhdarchoid pterosaur Chaoyangopterus zhangi (Wang \& 115 Zhou, 2003b), the istiodactyliform pterosaur Hongshanopterus lacustris (Wang et al., 2008), the 116 istiodactylid Nurhachius luei (Zhou et al., 2019), the dromaeosaurid Microraptor gui (Xu et al. 117 2003), the enanthiornithines Dapingfangornis sentisorhinus (Li et al., 2006) and Longipteryx 118 chaoyangensis (Zhang et al., 2001), the non-pygostylian avebrevicaudan Sapeornis 119 chaoyangensis (Zhou \& Zhang, 2002a), the jeholornithiform Jeholornis prima (Zhou \& Zhang, 120 2002b; 2003), the ornithuromorph Yanornis martini (Zhou et al., 2004), and the squamate 121 Yabeinosaurus tenuis (Evans et al., 2005).

122

123

124 125

126

127

128

129

130

131

132

133

134

135

136 137

\section{Anatomical terminology}

In the present study, anatomical terms follow Romerian nomenclature and orientation, using anterior/posterior instead of cranial/caudal (e.g. Wilson, 2006). The standardization of the orientation of wing elements is based on inferred flight position, following Bennett (2001).

\section{Reference phylogenetic proposal and systematic terminology}

The present study follows the reference phylogenetic proposal, and consequent systematic terminology, that tapejarines and thalassodromines are sister-groups (Kellner \& Campos, 2007; Vullo et al., 2012; Pêgas et al., 2018; 2021). Together, they form the Tapejaridae sensu Kellner \& Campos (2007). Under alternative proposals, the Tapejaridae sensu Lü et al. (2006a) comprise tapejarines sensu Kellner \& Campos (2007) but excludes thalassodromines. Tapejarids sensu Lü et al. (2006a) are interpreted as a basal group of azhdarchoids, with thalassodromines being more closely related to azhdarchids + chaoyangopterids than to tapejarines - for such alternative proposals, we refer the readers to Lü et al. (2008) and Andres et al. (2014). 


\section{Institutional abbreviations}

BMNH (=BPV), Beijing Museum of Natural History, Beijing, China; BXGM, Benxi Geological Museum, Benxi, China; D, Dalian Natural History Museum, Dalian, China; GMN, Geological Museum of Nanjing, Nanjing, China; IVPP, Institute of Vertebrate Paleontology and Paleoanthropology, CAS, Beijing, China; JPM (=JZMP), Jinzhou Paleontological Museum, Jinzhou, China; PMOL (=LPM), Paleontological Museum of Liaoning, Shenyang, China; XHPM, Xinghai Paleontological Museum, Dalian, China; ZMNH, Zhejiang Museum of Natural History, Hangzhou, China.

\section{Results}

\section{Description of new specimen D3072}

Generalities. The specimen is represented by an almost complete postcranial skeleton preserved on a single slab (Fig. 1, Table 1). The skull, pelvic region and femora are missing. These missing elements (at least the pelvis, sacral vertebrae and femora) might, presumably, have been retained in a counter-slab. Preservation quality varies throughout the skeleton. While some elements are articulated and maintain their natural positions (such as the main wing bones, humerus, radius and ulna, carpals, metacarpal IV and digit IV), some other elements are slightly displaced (especially the scapula and coracoid, but also some small manual and pedal elements).

Cervical series. Apart from the atlas and axis, the remaining elements of the cervical series are preserved. All mid-cervicals (cervicals III-VII) are exposed in left lateral view (Fig. 2). These vertebrae are relatively elongate (length/height ratio 1.5-2.5; Table 1), slightly more so than in Tapejara wellnhoferi or thalassodromines (length/height ratios of, respectively, 2 and 0.9-1.9; see Vila Nova et al., 2015; Leal et al., 2018), but less so than in chaoyangopterids (ratios 2-3; see Wu et al., 2017; Leal et al., 2018) or azhdarchids (ratios 4-10; see Padian 1984; Andres et al., 2014; Leal et al., 2018; Naish \& Witton, 2017; Pêgas et al., 2021). Cervical IV is the longest one, as measured from the tips of the prezygapophyses to the tips of the postzygapophyses (Table 1). 
164 The preserved cervical vertebrae length formula is III $<$ IV $>$ V $>$ VI $>$ VII $>$ VIII $>$ IX. This 165 formula differs from other azhdarchoid taxa. In Tapejara wellnhoferi, cervicals IV and V are of 166 subequal length. According to Kellner \& Hasegawa (1993), the same is true for Tupuxuara 167 leonardii, but for the sake of precision, we note that in fact cervical $\mathrm{V}$ is slightly longer than cervical IV in this taxon (RVP, pers. obs.). The same is true for chaoyangopterids and azhdarchids, in which cervical V is the longest (Lü et al., 2008; Averianov, 2010; Wu et al. 2017; Leal et al., 2018). There are no mid-cervical ribs.

The neural spine is relatively low, similar to what is seen in Tapejara and thalassodromines (Vila Nova et al., 2015), which is lower than in pteranodontoids (e.g. Kellner \& Tomida, 2000; Bennett, 2001) but not as low as in chaoyangopterids (Wu et al. 2017; Leal et al., 2018) nor as in azhdarchids in which the neural spine is only a vestigial ridge (e.g. Averianov, 2010).

A single, small pneumatic foramen can be seen on the lateral surfaces of the third, fourth and fifth cervical vertebrae; the status on the sixth and seventh is unclear due to crushing. This foramen is located just below the zygapophyseal ridge, presumably near (ventral to) the contact region between centrum and neural arch. This is similar to the condition seen in Tapejara wellnhoferi, in which a single pneumatic foramen on the lateral surface of the mid-cervical vertebrae is present (Vila Nova et al., 2015), while two or three are present in thalassodromines (Vila Nova et al., 2015; Buchmann et al., 2017) and none in chaoyangopterids and azhdarchids (Averianov, 2010; Wu et al. 2017; Leal et al., 2018; Buchmann \& Rodrigues, 2019). Despite the crushed nature of specimen D3072, the openings observed on the lateral surface of these vertebrae match well in size, shape, and location the pneumatic foramina found in the midcervical vertebrae of Tapejara wellnhoferi (Eck et al., 2011; Vila Nova et al., 2015), leading us to interpret these openings in D3072 as pneumatic foramina as well. The tentative identification of a possible lateral pneumatic foramina on the mid-cervicals of Sinopterus was already mentioned by Vila Nova et al. (2015), inferred from a depression seen in cervical VII of the holotype of Sinopterus dongi. Zhang et al. (2017) reported on the presence of this feature in 
IVPP V 23387, a specimen they referred to Sinopterus atavismus. The same condition is seen in the holotype of Sinopterus lingyuanensis (Lü et al., 2016).

Some details of the mid-cervical vertebrae are obliterated due to crushing. The ventral margins seem to be slightly damaged. In cervical VII, the ventral margin of the centrum is concave, with a relatively large hypapophysis, similar to the condition seen in Tapejara (Vila Nova et al., 2015). The status in other mid-cervicals is unclear. All mid-cervicals bear well-developed postexapophyses. Cervicals VIII and IX are exposed in a somewhat ventrolateral view and not much can be seen (Fig. 3).

Dorsal series. There are 11 preserved dorsal vertebrae (Fig. 3). The anterior margin is concave and the posterior margin is convex. The first three dorsal vertebrae seem to exhibit fused centra and neural arches. Dorsal vertebrae 4 and 5 are not very discernible due to crushing. Although some overlying bones and sediment still obscure most of the centra, a contiguous series of transverse processes can be seen, from dorsal vertebrae 1 through 13. A single centrum (probably from dorsal vertebra 6 , since is lies ventrally to the sixth dorsal neural arch) is displaced from this contiguous series of neural arches, indicating it was not fused to its respective neural arch. The posterior dorsal vertebrae (7-11) also exhibit an open suture between centra and neural arches. This indicates that, while in mid-cervical vertebrae and anterior dorsal vertebrae the centra were fused to the neural arches, the same was not true for mid- and posterior dorsals. A similar condition was found in the juvenile Tapejara wellnhoferi specimen SMNK PAL 1137, in which the preserved cervical vertebrae were entirely fused, while the single preserved dorsal vertebrae lacked fusion between centrum and neural arch (Eck et al., 2011). In dorsal vertebrae 1 and 2, it can be seen that a well-developed fossa is present at the ventral surface of the transverse process base.

Scapula. The left scapula is preserved medial to the left humerus, in an approximately ventral view (Fig. 3). It is not fused to the coracoid, which is displaced from it. Not much can be observed due to crushing. The shaft of the scapula is wider than that of the coracoid. The scapula 
216 is slightly bowed ventrodistally, similarly to Tapejara wellnhoferi (Eck et al., 2011),

217 Caupedactylus ybaka (Kellner, 2013) or Keresdrakon vilsoni (Kellner et al., 2019).

218 Coracoid. The left coracoid is exposed in dorsal view (Fig. 3). It is curved with an expanded 219 medial end. The medial end is bifid, terminating in an anterior and a posterior eminence, which 220 form the saddle-shaped sternal articulation. These two eminences are approximately equivalent 221 in size, unlike Tapejara wellnhoferi (Eck et al., 2011), Caupedactylus ybaka (Kellner, 2013), 222 Caiuajara dobruskii (Manzig et al. 2014) or Keresdrakon vilsoni (Kellner et al., 2019) in which 223 the posterior eminence is slightly larger than the anterior one.

224 Humerus. Both humeri are preserved approximately in ventral view (Fig. 4). The left humerus is preserved in a better condition than the right one, in which the ulnar crest, deltopectoral crest and distal region are slightly damaged. The shaft of the humerus is straight. The deltopectoral crest is subrectangular in profile and is located proximally. The ventral margin is straight. It forms an approximately perpendicular angle relative to the main shaft. This is similar to Caupedactylus ybaka (Kellner, 2013) and Tupuxuara leonardii (Witton et al., 2009), and slightly different from Tapejara wellnhoferi, Cainajara dobruskii and Tupandactylus navigans, in which the deltopectoral crest is at a slightly oblique angle to the humeral shaft, ventromedially oriented (Eck et al., 2011; Manzig et al., 2014; Beccari et al., 2021). The region of the humeral head, in ventral view, is marked by a triangular eminence. The ulnar crest is rounded and posterodorsally flared (so that it is well visible in ventral view), similarly to Tapejara wellnhoferi and Caiuajara dobruskii (Eck et al., 2011; Manzig et al., 2014). A distinct foramen is present on the ventral proximal end of the humerus, close (slightly distal to) the humeral head, between the deltopectoral and ulnar crests. This is similar to other azhdarchoids in general, as can be seen in Tapejara wellnhoferi (Eck et al., 2011), Caiuajara dobruskii (Manzig et al., 2014), Tupandactylus navigans (Beccari et al., 2021), Caupedactylus ybaka (Kellner, 2013), Tupuxuara leonardii (Kellner \& Hasegawa, 1993), Keresdrakon vilsoni (Kellner et al., 2019), and azhdarchids (Lawson, 1975; Hone et al., 2019). The humeral shaft slightly expands towards the 
242 distal end. Two humeral epiphyses are present on the left side. They are unfused to the humerus 243 and preserved near the proximal region of the ulna. Since they are displaced from the humerus, 244 their relative orientation is unclear.

245

246

247

Radius. The ulna and radius are preserved parallel to each other on both sides. The diameter of the ulna is larger than that of the radius. A precise ratio cannot be given, since the ulna partially overlaps the radius on both sides, but the radius seems to be, roughly, not less than half the diameter of the ulna. Not much can be observed on the right side, since the ulna and radius are too compressed against each other, and the proximal and distal regions are slightly damaged. The left side can be better observed, although crushing still obscures some details. The left radius and ulna are exposed in an approximately anteroventral view.

The proximal region of the left radius bears a concave proximal margin (Fig. 5). The proximal surface itself bears a cotyle. Two eminences can be seen, an anterodorsal and a posteroventral one. The anterodorsal one (the biccipital process) is smaller than the posteroventral one and projects only gently anterodorsally, similarly to Tapejara wellnhoferi (Eck et al., 2011) and Jidapterus edentus ( $\mathrm{Wu}$ et al., 2017). The posteroventral one, which is larger, projects proximally, more so than in Tapejara wellnhoferi (Eck et al., 2011) or Jidapterus edentus (Wu et al., 2017) in which it is less projected, or in Pteranodon in which it is rather inconspicuous (Bennett, 2001). The distal end of the radius is slightly expanded, but not much can be seen due to crushing.

Ulna. The left ulna is better preserved than the right one, as mentioned above. The shaft is straight. On the proximal end, a dorsal, large eminence projects proximally, presumably for the attachment of M. triceps brachii (Fig. 5). This eminence is particularly prominent, more so than in Tapejara wellnhoferi (Eck et al., 2011), Jidapterus edentus (Wu et al., 2017) or Pteranodon (Bennett, 2001). Ventral to this eminence, the capitular and trochlear cotyles can be seen, separated by a discrete ridge. They both face proximally. Their shapes and dimensions cannot be assessed confidently, since the region has been very compressed. On the distal end, two 
268

269

270

271

272

273

274

275

276

277

278

279

280

281

282

283

284

285

286

287

288

289

290

291

292

293

collateral processes can be seen, a dorsal and a ventral one (Fig. 5). The dorsal one is much less developed than the ventral one, similarly to Tapejara wellnhoferi (Eck et al., 2011) and the possible tapejarid "Santanadactylus spixii" (Wellnhofer, 1987; Kellner \& Tomida, 2000) and unlike Pteranodon in which they are roughly subequal (Bennett, 2001). The dorsal articular surface, in the form of a gentle depression, can be seen on the distal surface of the dorsal collateral process. The olecranon process is only slightly prominent, similar to Pteranodon (Bennett, 2001) and unlike "Santanadactylus spixii" and Tapejara wellnhoferi in which it is larger and more prominent (Wellnhofer, 1987; Eck et al., 2011). Further details on the proximal surface are unclear due to crushing.

Carpals. Both left and right carpal regions are preserved. On the left region, the bones are less crushed, and it is clear that all carpal elements are unfused, although not much information can be retrieved (Fig. 5). On the right side, the elements are very compressed against each other and their limits thus became unclear, except for the preaxial carpal and pteroid which are slightly displaced (Fig. 6). The pteroid can be seen on both sides. On the left side, it is almost complete, lacking only the very apex tip. It is exposed in anterior view. It is thin, rod-like and elongated. The shaft is gently bowed, and the base is slightly expanded. On the right side, only a small fragment of the bone is preserved, also not in natural position.

Metacarpals. Metacarpals I-III are slender, thin, rod-like bones, while metacarpal IV is robust as in other pterosaurs. Metacarpal I is not entirely preserved, as attested by a missing mid-shaft portion (Fig. 6). Still, it extends for about $90 \%$ the distance between its distal tip and the carpal region. The proximal tip seems to be damaged and it is likely that it extended further proximally, possibly onto the carpal region, contacting it, as has been reported for the holotypes of Sinopterus dongi and "Huaxiapterus" jii (Wang et al., 2003; Lü \& Yuan, 2005). Metacarpals II and III are comparatively shorter, extending for about a third of metacarpal IV. They are pointed proximally, and slightly expanded distally. Metacarpal IV is wider proximally than distally. The distal region exhibits the typical trochlear-like morphology that is seen in pterosaurs, with a pair 
294 of condyles, a dorsal one and a ventral one (e.g. Wellnhofer, 1978). Not much details can be seen 295 on the condyles due to crushing.

296 Free digits. On the right side, the manus is almost entirely preserved, except for the second 297 phalanx of digit 3 (Fig. 6). On the left side, only two phalanges are present for each digit, the two 298 phalanges of digit one and the two distal ones of digits 2 and 3 (Fig. 1). The digits become 299 progressively slightly longer from 1 to 3 . The proximal phalanx of right digit 1 has a welldeveloped trochlear-like articulation with two small condyles on the proximal tip. The condition in the other proximal phalanges is unclear. The first digit bears only two phalanges (the proximal phanalx and the ungual), as typical of pterosaurs (e.g. Wellnhofer, 1978). The second digit bears three phalanges. On the third digit, only three phalanges are preserved, although the typical condition in pterosaurs is the presence of four phalanges (e.g. Wellnhofer, 1978). The proximal phalanx is disarticulated, displaced from its natural position. The two distalmost phalanges are articulated to each other, from a distance from the proximal element. It is plausible that the third phalanx of digit 3, which is typically small and square-like, has been displaced and possibly obscured by the other elements. The manual claws are long and recurved. They are slightly larger than the pedal claws, with relatively larger flexor tubercles as well.

Wing digit. Wing phalanges I-IV decrease in length progressively from I to IV (Fig. 1). Phalanges 1-3 are straight. On the ventral surface of the proximal end of the right first phalanx, two pneumatic openings are present, one on the posterior region and another on the anterior region. Such feature has only ever been reported for the azhdarchoid Keresdrakon vilsoni (see Kellner et al., 2019). The fourth wing phalanx (as seen on both left and right sides) is distinctively curved, as seen in Eopteranodon lii (Lü \& Zhang, 2005; Lü et al., 2006b) and the holotypes of Sinopterus dongi (Wang \& Zhou, 2003a), S. jii (Lü et al., 2005) and "H." atavismus (Lü et al., 2016), but unlike "Huaxiapterus” corollatus in which it is straighter (Lü et 318 al., 2006a).

Tibia. The right tibia is highly damaged, with displaced splints of crushed bone along its shaft. 
320 The left tibia lacks the proximal region. As can be seen on both sides, neither the fibula nor the

321 proximal tarsals are fused to the tibia (Fig. 7). The tibia is broader proximally than distally.

322 Fibula. On both sides, it can be seen that the fibula is not fused to the tibia. The fibula is present

323

324

325

326

327

328

329

330

331

332

333

334

335

336

337

338

339

340

341

342

343 as a very thin, elongate bone, parallel to the tibia. It runs through, approximately, a third the length of the tibia.

Tarsus. The tarsus can be observed on both sides (Fig. 7). Two proximal and two distal elements are present on the left pes, all slightly displaced from their presumed natural positions. On the right pes, the lateral proximal tarsal and both distal tarsals are preserved. The medial proximal tarsal is not preserved. A small, rounded, unidentified bone is present. The proximal tarsals are not fused to the tibia. On both sides, the lateral proximal tarsal is approximately rectangular and is the largest tarsal element, as in IVPP V 23388-V (Zhang et al. 2019).

Metatarsus. Metatarsals I-IV are elongate, slender bones, slightly expanded at the ends (Fig. 7). The proximal ends are broader than the distal ones, particularly in metatarsal IV. They are progressively shorter from I to IV, as in the holotype of Sinopterus dongi (Wang \& Zhou, 2003a) and unlike other purported species of the Sinopterus complex (Zhang et al., 2019). Metatarsal V is reduced and hook-shaped, with a broad proximal region and a pointed distal apex. It articulates with the lateral distal tarsal.

Pedal digits. The pedal formula can be inferred to be 2-3-4-5-1 (Fig. 7). The length ratio of metatarsal III to tibia is 0.24 . The pedal claws and the manual claws have roughly the same shape, except that the manual claws are slightly larger and bear slightly larger flexor tubercles. A keratinous ungual sheath is preserved on right pedal digit 4 (Fig. 7). The fifth digit is represented by a single, extremely reduced phalanx, which is preserved on the left side.

\section{Discussion}


344

345

346

347

348

349

350

351

352

353

354

355

356

357

358

359

360

361

362

363

364

365

366

367

368

369

\section{Identification of specimen D3072}

Based on the relatively low level of postcranial bone fusion, it is clear that specimen D3072 is a juvenile. The new specimen lacks fusion of: the humeral epiphyses, scapulocoracoid, the extensor tendon process of the first wing phalanx, the carpal elements, tibia and fibula, tibia and proximal tarsals, and neural arches and centra of most dorsal vertebrae. The only postcranial elements that are fused are the neural arches and centra of cervical vertebrae and anterior dorsal vertebrae. Despite the uncertainties surrounding studies on the ontogeny of pterosaurs (see Kellner, 2015; Dalla Vecchia, 2018) and reptiles overall (Griffin et al., 2020), such low level of skeletal fusion is indicative of a juvenile nature for this specimen (e.g. Bennett, 1993; Kellner, 2015; Dalla Vecchia, 2018; Griffin et al., 2020). With a wingspan of about $1134 \mathrm{~mm}$, D3072 is similar in size to holotype of Sinopterus dongi, which is also a juvenile, with $1200 \mathrm{~mm}$ in wingspan (Wang \& Zhou, 2003a), and slightly larger than other juveniles such as the holotypes of S. gui (with $\sim 800 \mathrm{~mm}$ in wingspan; Li et al., 2003) and “H." atavismus ( $\sim 50 \mathrm{~mm}$ in wingspan; Lü et al., 2016). These are substantially larger than the possible near-hatchling Sinopterus specimen represented by the holotype of Nemicolopterus crypticus (Witton, 2013; Naish et al., 2021), with a wingspan of $\sim 250 \mathrm{~mm}$. In contrast, D3072 is considerably smaller than subadult specimens referred to the genus Sinopterus such as BXGM V0011 and IVPP V 23388, both with $1600 \mathrm{~mm}$ in wingspan (Lü et al., 2007; Zhang et al., 2019), or the adult specimen D2525, with $2000 \mathrm{~mm}$ in wingspan (Lü et al., 2006c).

The new specimen D3072 is flattened, preserved on a slab, as typical of Jehol fossils (e.g. Pan et al., 2013; Xu et al., 2020) and many other pterosaur remains from around the world (e.g. Beccari et al., 2021). This frequent preservation style in pterosaurs turns anatomical comparisons relatively hard, since it limits what bone surfaces can, or not, be viewed (e.g. in D3072, the anterior and posterior views of the cervical vertebrae cannot be seen, nor the distal surface of the humerus). Despite this obstacle, there are a number of observable features in specimen D3072 that allow its identification. It exhibits a subrectangular, non-warped deltopectoral crest of the 
370 humerus, typical of the Tapejaroidea sensu Kellner (2003). Specimen D3072 further exhibits

371 features that are found in tapejarines such as mid-cervical vertebrae comparatively short with

372 low (but not ridge-like) neural spines and a single pneumatic foramen on the lateral surface (Vila

373 Nova et al., 2015), as well as a dorsally flared ulnar crest of the humerus similar to Tapejara and

374 Caiuajara (Eck et al., 2011; Manzig et al., 2014). Together, all of these features are found only

375 in tapejarines such as Tapejara (e.g. Eck et al., 2011; Vila Nova et al., 2015), Caiuajara

376 (Manzig et al., 2014) and Sinopterus (Wang \& Zhou, 2003a; Lü et al., 2016; Zhang et al., 2019).

377 Limb proportions also match the typical condition seen in tapejarines, including Sinopterus

378 dongi (see Vila Nova et al., 2012).

The fact that specimen D3072 is a tapejarine coming from the Jiufotang Formation indicates that it likely belongs within the Sinopterus complex. The next question is whether it matches, or not, any of the proposed species of Sinopterus. Under the expansive scheme defended by Zhang et al. (2019), there is reason to regard D3072 as a specimen of Sinopterus dongi: this new specimen exhibits a metatarsal I longer than metatarsals II-IV, which are progressively shorter.

This feature is absent in other proposed species of the genus, and is suggested as a diagnostic feature of Sinopterus dongi under the expansive scheme (Zhang et al., 2019). Furthermore, regarding limb proportions, specimen D3702 closely matches the holotype of Sinopterus dongi, (Wang \& Zhou, 2003; Vila Nova \& Sayão, 2012; see also Fig. 8). Under the conservative scheme proposed by Witton (2013) and preliminarily defended by Naish et al. (2021), there is also no reason to regard D3072 as distinct from the type-species Sinopterus dongi, with which it shares pedal morphology and similar limb proportions. Thus, under either scheme, specimen D3072 can confidently be attributed to the species Sinopterus dongi. How many further

Sinopterus species are valid or not, as well as their respective diagnostic features, are matters to be explored elsewhere, pending detailed accounts of the comparative osteology of further specimens. 
396

397

398

399

400

401

402

403

404

405

406

407

408

409

410

411

412

413

414

415

416

417

418

419

420

421

\section{Comments on the osteology of Sinopterus dongi and implications}

The new specimen D3072 sheds fresh light on the osteology of Sinopterus dongi, corroborating previous suggestions and revealing new data. For instance, Vila Nova et al. (2015) were the first authors to suggest that pneumatic foramina were most likely present on the lateral surface of the centrum in Sinopterus, which were previously regarded as absent (Lü et al., 2006b; Liu et al., 2015). Later, Zhang et al. (2019) reported on the presence of this feature for IVPP V 23388 (therein referred to $S$. atavismus), but refrained from attesting its presence in other species of Sinopterus. In D3072, this feature is clearly preserved, suggesting that it was most likely common for all potential Sinopterus species. Specimens where it cannot be seen are probably simply affected by taphonomy, such as the holotype of $S$. dongi, as suggested by Vila Nova et al. (2015).

A purportedly distinctive scapula, described as strongly curved, has been considered as a diagnostic feature of Sinopterus (Wang \& Zhou, 2003a; Zhang et al., 2019), although it has not been demonstrated how such strong curvature differs from what is seen in other pterosaurs. If compared to other tapejarines, the curvature seen in the scapula of Sinopterus dongi (as seen from anterior or posterior views) is comparable to what is seen in Tapejara wellnhoferi (Eck et al., 2011), Caupedactylus ybaka (Kellner, 2013) and Caiuajara dobruskii (Manzig et al., 2014). If compared to other azhdarchoids, it is also comparable to the chaoyangopterid Jidapterus edentus (Wu et al., 2017).

The coracoid, in turn, does seem to be distinctive in Sinopterus dongi if compared to other tapejarines. The coracoid of D3072 is notably bowed in dorsal view, more so than in Tapejara, Caupedactylus or Caiuajara (Eck et al., 2011; Kellner, 2013; Manzig et al., 2014). The proximal pair of eminences also exhibit a distinguishing condition, being similar in size, unlike Tapejara, Caupedactylus or Caiuajara in which posterior eminence is slightly larger than the anterior one. The condition in further proposed species of the Sinopterus complex remains to be described. This feature is thus of interest for future comparative studies involving Jiufotang tapejarines. 
422

423

424

425

426

427

428

429

430

431

432

433

434

435

436

437

438

439

440

441

442

443

444

445

446

447

The overall anatomy of the humerus agrees well with Tapejara (see Eck et al., 2011) and Caiuajara (see Manzig et al., 2014), due to the presence of an approximately straight shaft, a rectangular deltopectoral crest, a humeral head eminence that is triangular in ventral view, and a rounded, dorsally flared ulnar crest. This last character is absent in other azhdarchoids such as Caupedactylus (Kellner, 2013), Tupuxuara (Witton et al., 2009) and azhdarchids (Witton et al., 2009) in which the ulnar crest is trapezoidal and posteriorly oriented, and this feature is thus of potential phylogenetic relevance for tapejarines. Furthermore, Sinopterus dongi differs from Tapejara, Cainajara and Tupandactylus in exhibiting a deltopectoral crest of the humerus which is perpendicular to the humeral shaft, while in Tapejara, Caiuajara and Tupandactylus it is slightly oblique, slanting proximally (Eck et al., 2011; Manzig et al., 2014; Beccari et al., 2021; see also Fig. 9). Future comparative and phylogenetic studies should take these features into account.

In the new specimen D3072, metacarpal I is very elongate and, as mentioned above, probably contacted the carpus, as in the holotypes of Sinopterus dongi and "Huaxiapterus" jii (Wang et al., 2003; Lü \& Yuan, 2005). This feature is worthy of further investigation, since a short metacarpal I (extending for only a third of the length of metacarpal IV) is a potential distinguishing feature between "Huaxiapterus" (as in the holotypes of "H." benxiensis and "H." corollatus) and other Sinopterus species (Kellner \& Campos, 2007). Future assessments of the holotypes of “H.” benxiensis and "H." corollatus are needed in order to verify this feature, by investigating whether it is a natural feature or a potential preservation artifact.

Interestingly, the proximal region of the first wing phalanx of D3072 presents two ventral pneumatic foramina, an anterior and a posterior one. This differs from other tapejarines such as Tapejara wellnhoferi (Eck et al., 2011), Caupedactylus ybaka (Kellner, 2013) and Caiuajara dobruskii (Manzig et al., 2014). It also differs from the thalassodromine Tupuxuara leonardii (RVP, pers. obs.) and the chaoyangopterid Jidapterus edentus (Wu et al., 2017), in which a single foramen is present. A pair of foramina on the ventral side of the first wing phalanax 
448

449

450 proximal region has been reported only for the azhdarchoid Keresdrakon (Kellner et al., 2019). Because of this peculiarity, it is worth investigating how widespread is this feature within Jiufotang tapejarines, what may prove useful in future revisions of the Sinopterus complex.

Another interesting feature observable in the new specimen D3072 is the ungual sheath preserved on the right pedal digit 4 (Fig. 7). The sheath extends for about $50 \mathrm{~mm}$, which is about $85 \%$ the length of the bony ungual. Keratinous sheaths in tapejarid unguals were previously known only from an incomplete skeleton from the Crato Formation, SMNK PAL 3830, which also exhibits an elongate and well-recurved ungual sheath (Frey et al., 2003). Specimen D3072 represents the first case of ungual sheath preservation in a Chinese tapejarid. Tapejarine tapejarids such as Sinopterus specimens from the Jiufotang Formation, as well as SMNK PAL 3830, are known to exhibit ungual phalanges that are particularly robust and recurved if compared to other pterosaurs such as pteranodontoids, azhdarchids and chaoyangopterids ( $\mathrm{Wu}$ et al., 2017). The robust, recurved unguals of tapejarines have been interpreted as potentially related to scansorial or arboreal habits, by favoring climbing of tree trunks (Wang \& Zhou, 2003a). This interpretation was corroborated by morphometric analyses by $\mathrm{Wu}$ et al. (2017), which revealed that, while chaoyangopterid unguals are consistent with those of ground-dwelling tetrapods, those of tapejarines were consistent with those of tetrapods with specialized claws for arboreal, scansorial, or predatory lifestyles (Wu et al., 2017). The new specimen D3072 shows that, in life, the pedal claws of Sinopterus were substantially longer and more recurved than suggested by bone alone (as in SMNK PAL 3830), due to a significantly elongate horny sheath. This further highlights the specialized morphology of tapejarine unguals, possibly related to arboreal or scansorial habits (Wu et al., 2017).

\section{Short comments on the Sinopterus complex}

Peer] reviewing PDF | (2021:07:64216:1:1:NEW 18 Sep 2021) 
473 the description of Sinopterus dongi (Wang \& Zhou, 2003a), further 6 species were named until 4742016 (see Lü et al., 2016). Witton (2013) raised the concern that all Jiufotang tapejarines could 475 represent an ontogenetic continuum of a single species (including also Nemicolopterus crypticus, 476 interpreted as a potential hatchling specimen). Later on, further two new species were proposed: 477 Sinopterus lingyuanensis and "Huaxiapterus" atavismus (Lü et al., 2016), which were later 478 regarded as valid (both under the genus Sinopterus) by Zhang et al. (2019), who recognized at 479 least five valid species for Sinopterus. More recently, Naish et al. (2021) corroborated the 480 proposition of Witton (2013) that most, if not all, proposed species could be conspecific 481 (including the most recently named ones, Sinopterus lingyuanensis and "Huaxiapterus"

482

atavismus). These authors demonstrated that all Jiufotang tapejarines seemed to fall within a single spectrum of variation, as demonstrated by trends in limb and crest proportions (Naish et al., 2021). However, they expressed caution regarding this proposition. Naish et al. (2021) noticed that the holotype of "Huaxiapterus" corollatus seems to be an outlier regarding limb proportions and, thus, could represent a second taxon. These authors further reiterated that, before the taxonomy of the Sinopterus complex can be resolved, a detailed anatomical reassessment of the known specimens is needed (Naish et al., 2021).

In the present work, we concur with the observations and preliminary conclusions provided by Naish et al. (2021) regarding these issues. We regard that there is strong evidence for a taxonomic overspliting in the Sinopterus complex, although it is still possible that more than one taxon is present in the known sample of Jiufotang tapejarines (see Naish et al., 2021). In order to try to untangle the Sinopterus complex, a detailed comparative reassessment of all known specimens is thus paramount. However, before known specimens can be compared, detailed accounts of their osteology need to be provided. So far, few works have focused on the detailed osteological description of Sinopterus specimens (e.g. Zhang et al., 2019). Detailed osteological redescriptions are thus much needed for most of the known specimens (such as the types of Sinopterus gui, Sinopterus lingyuanensis and Huaxiapterus atavismus). Given the importance of osteological descriptions as foundations for subsequent taxonomic decisions and systematic 
500

501

502

503

504

505

506

507

508

509

510

511

512

513

514

515

516

517

518

519

520

521

522

523

524

studies, in the present contribution we aimed at providing osteological data for the new specimen D3072.

Here, we corroborate the presence of several features in Sinopterus dongi: pneumatic foramina piercing the lateral surface of mid-cervical vertebrae, a metacarpal I reaching the carpus, and a metatarsal I longer than subsequent metatarsals. Based on the configuration of metacarpal I, it does seem plausible that multiple species of Sinopterus could be present in the Jiufotang assemblage, and not a single one. Further examination of the already known specimens, with detailed descriptions, are needed in order to confirm whether the variation in metacarpal I is natural or, perhaps, preservational. Based on metatarsal proportions, it does also seem plausible that not all Sinopterus specimens are conspecific, and that, instead, more than one species is present. Still, detailed accounts of these variations still need to be performed taking into account the entire sample of known specimens.

From this point on, further anatomical accounts concerning the other proposed species must be made. With time, this should allow a better understanding of osteological variation in the Sinopterus complex and, subsequently, lead to a revised taxonomic scheme for the genus. Hopefully this study will serve as a comparative basis for future works focusing on the osteology and taxonomy of the Sinopterus complex.

\section{Conclusions}

The new specimen D3072 represents a postcranial skeleton of a Jiufotang tapejarine. Under both the conservative and expansive taxonomic approaches that presently exist regarding the Sinopterus complex, specimen D3072 is attributable to Sinopterus dongi, with which it shares almost identical limb proportions and pedal morphology, with metatarsal I being the longest. The osteological description we provide for this new specimen sheds new light on the anatomy of Sinopterus, which should be helpful for future systematic studies as well as a taxonomic revision 
525

526

527

528

529

530

531

532

533

534

535

536

537

538

539

540

541

542

543

544

545

546

547

548

549

Acknowledgements

Peer] reviewing PDF | (2021:07:64216:1:1:NEW 18 Sep 2021)

of the Sinopterus complex. Crato tapejarid SMNK PAL 3830. Formation.

\section{Acknowledgements}

In the present study, we confirm the presence of pneumatic foramina on the lateral surface of mid-cervical vertebrae in Sinopterus dongi. We further report that this taxon distinguishes itself from Tapejara wellnhoferi (the next best-known tapejarine so far) in that cervical IV is the longest one, the two proximal coracoid eminences are similar in size, the deltopectoral crest of the humerus is perpendicular to the humeral shaft, and that two ventral pneumatic foramina are present on the proximal region of wing digit 1. We also note that Sinopterus dongi shares with Tapejara wellnhoferi, as well as Caiuajara dobruskii, some features that are absent outside of the Tapejarinae within azhdarchoids, such as a rounded and dorsally flared ulnar crest of the humerus, a single and small pneumatic foramen on the mid-cervical vertebrae, and a welldeveloped hypapophysis. We further report for the first time an ungual sheath in a pedal ungual of Sinopterus dongi. It demonstrates that these structures were well-developed in this taxon, further enhancing the elongation and the curvature of the pedal claw, similar to the indeterminate

The conditions of all of these features remain to be assessed in other purported species of the Sinopterus complex, as well as on other tapejarids that were only preliminarily described such as Caiuajara dobruskii (Manzig et al. 2014) and Tupuxuara leonardii (Kellner \& Hasegawa, 1993), and also taxa for which postcranial skeletons are still unknown (such as Tupandactylus spp. or Europejara olcadesorum). Accounts on the osteology of these other forms will be needed in order to assess potential diagnostic and phylogenetic signals in these features, which is possibly a promising issue to explore. We hope the osteological data presented here will serve as basis for comparative studies exploring further tapejarines overall, and especially those from the Jiufotang 
550 For access to specimens under their care, C.S. thanks Fangfang Teng (XHPM); R.V.P thanks

551 Xiaolin Wang (IVPP), Shunxing Jiang (IVPP), Dieter Schreiber (SMNK), and Eberhard Frey

552 (SMNK); and X.Z. thanks Xinsheng Jin (ZMNH), Qiannan Zhang (BMNH), Shaowen Zhang

553 (CAGS), Jun Zhang (BXGM), Honggang Huo (BXGM), and Deyu Sun (JPM). R.V.P thanks

554 Maria E. Leal, Lucy Souza and Kamila Bandeira for fruitful discussions.

References

557

Andres B, Ji Q. 2008. A new pterosaur from the Liaoning Province of China, the phylogeny of the Pterodactyloidea, and the convergence in their cervical vertebrae. Palaeontology, 51: 453-469.

Andres B, Clark JM, Xu X. 2014. The earliest pterodactyloid and the origin of the group. Current Biology, 24(9): 1011-1016.

Averianov AO. 2010. The osteology of Azhdarcho lancicollis Nessov, 1984 (Pterosauria, Azhdarchidae) from the late Cretaceous of Uzbekistan. Proceedings of the Zoological Institute RAS, 314(3): 264-317.

Bennett SC. 1993. The ontogeny of Pteranodon and other pterosaurs. Paleobiology, 19(1): 92106.

Bennett SC. 2001. The osteology and functional morphology of the Late Cretaceous pterosaur Pteranodon Part I. General description of osteology. Palaeontographica Abteilung A 2001:1-112.

Buchmann R, Rodrigues T, Polegario S, Kellner AWA. 2018. New information on the postcranial skeleton of the Thalassodrominae (Pterosauria, Pterodactyloidea, Tapejaridae). Historical Biology, 30(8): 1139-1149.Buchmann R, Rodrigues T. 2019. The evolution of pneumatic foramina in pterosaur vertebrae. Anais Da Academia Brasileira De Ciencias, 91. 
576

577

578

579

580

581

582

583

584

585

586

587

588

589

590

591

592

593

594

595

596

597

598

599

600

601

602

Dalla Vecchia FM. 2019. Seazzadactylus venieri gen. et sp. nov., a new pterosaur (Diapsida: Pterosauria) from the Upper Triassic (Norian) of northeastern Italy. PeerJ, 7: e7363.

Evans SE, Wang Y, Li C. 2005. The Early Cretaceous lizard Yabeinosaurus from China: resolving an enigma. Journal of Systematic Palaeontology, 3: 319-335.

Eck K, Elgin RA, Frey E. 2011. On the osteology of Tapejara wellnhoferi Kellner 1989 and the first occurrence of a multiple specimen assemblage from the Santana Formation, Araripe Basin, NE-Brazil. Swiss Journal of Palaeontology, 130(2): 277.

Frey E, Tischlinger H, Buchy MC, Martill DM. 2003. New spec mens of Pterosauria (Reptilia) with soft parts with implications for pterosaurian anatomy and locomotion. In: E. Buffetaut and J.-M. Mazin (eds.), Evolution and Palaeobiology of Pterosaurs. Geological Society of London, Special Publications, 217: 233-266.

Griffin CT, Stocker MR, Colleary C, Stefanic CM, Lessner EJ, Riegler M, ..., Nesbitt SJ. 2021. Assessing ontogenetic maturity in extinct saurian reptiles. Biological Reviews, 96(2): 470-525.

Hone DW, Habib MB, Therrien F. 2019. Cryodrakon boreas, gen. et sp. nov., a Late Cretaceous Canadian azhdarchid pterosaur. Journal of Vertebrate Paleontology, 39(3): e1649681.

Kellner AWA. 2003. Pterosaur phylogeny and comments on the evolutionary history of the group. Geological Society, London, Special Publications, 217(1): 105-137.

Kellner AWA. 2013. A new unusual tapejarid (Pterosauria, Pterodactyloidea) from the Early Cretaceous Romualdo Formation, Araripe Basin, Brazil. Earth and Environmental Science Transactions of the Royal Society of Edinburgh, 103(3-4): 409-421.

Kellner AWA. 2015. Comments on Triassic pterosaurs with discussion about ontogeny and description of new taxa. Anais da Academia Brasileira de Ciências, 87: 669-689.

Kellner AWA, Campos DA. 2007. Short note on the ingroup relationships of the Tapejaridae (Pterosauria, Pterodactyloidea). Boletim do Museu Nacional, Nova Série, Rio de JaneiroBrasil. Geologia, 75: 1-14. 
Kellner AWA, Hasagawa Y. 1993. Postcranial skeleton of Tupuxuara (Pterosauria, Pterodactyloidea, Tapejaridae) from the Lower Cretaceous of Brazil. Journal of Vertebrate Paleontology, 13: 44A.

Kellner AWA, Tomida Y. 2000. Description of a new species of Anhangueridae (Pterodactyloidea) with comments on the pterosaur fauna from the Santana Formation (Aptian-Albian), Northeastern Brazil. National Science Museum, Tokyo, Monographs, 17: $1-135$.

Kellner AWA, Weinschütz LC, Holgado B, Bantim RA, Sayao JM. 2019. A new toothless pterosaur (Pterodactyloidea) from Southern Brazil with insights into the paleoecology of a Cretaceous desert. Anais da Academia Brasileira de Ciências, 91.

Lawson DA. 1975. Pterosaur from the Latest Cretaceous of West Texas: Discovery of the largest flying creature. Science, 185: 947-948.

Leal MEC, Pêgas RV, Bonde N, Kellner AWA. 2018. Cervical vertebrae of an enigmatic pterosaur from the Crato Formation (Lower Cretaceous, Araripe Basin, NE Brazil). Geological Society, London, Special Publications, 455(1): 195-208.

Li JJ, Lü JC, Zhang BK. 2003. A new lower Cretaceous sinopterid pterosaur from Western Liaoning, China. Acta Palaeontologica Sinica, 42: 442-447.

Li L, Ye D, Dongyu H, Li W, Shaoli C, Lianhai H. 2006. New eoenantiornithid bird from the early cretaceous Jiufotang formation of Western Liaoning, China. Acta Geologica Sinica-English Edition, 80(1), 38-41.

Liu DX, Zhou CF, Wang JQ, Li WG, Wei QW. 2015. New data on the cervical morphology of the Chinese tapejarine. Historical Biology, 27(6): 638-645.

Lü JC, Gao CL, Liu JY, Meng QJ, Ji Q. 2006b. New material of the pterosaur Eopteranodon from the Early Cretaceous Yixian Formation, western Liaoning, China. Geological Bulletin of China, 25: 555-571.

Lü JC, Gao YB, Xing LD, Li ZX, Sun ZY. 2007. A new species of Huaxiapterus from the Early Cretaceous of western Liaoning,China. Acta Geologica Sinica, 81(5): 683-687. 
630

631

632

633

634

635

636

637

638

639

640

641

642

643

644

645

646

647

648

649

650

651

652

653

654

655

656

Lü JC, Jin XS, Unwin DM, Zhao LJ, Azuma Y, Ji Q. 2006a. A new species of Huaxiapterus (Pterosauria: Pterodactyloidea) from the Lower Cretaceous of western Liaoning, China with comments on the systematics of tapejarid pterosaurs. Acta Geologica Sinica, 80(3): $315-326$.

Lü JC, Liu JY, Wang XR, Gao CL, Meng QJ, Ji Q. 2006c. New material of the pterosaur Sinopterus (Reptilia: Pterosauria) from the Early Cretaceous Jiufotang Formation, Western Liaoning, China. Acta Geologica Sinica, 80: 783-789.

Lü JC, Teng FF, Sun DY, Shen CZ, Li GQ, Gao X, Liu HF. 2016. The toothless pterosaurs from China. Acta Geologica Sinica, 90(9): 2513-2525.

Lü J, Unwin DM, Xu L, Zhang X. 2008. A new azhdarchoid pterosaur from the Lower Cretaceous of China and its implications for pterosaur phylogeny and evolution. Naturwissenschaften, 95(9): 891-897.

Lü JC, Yuan CX. 2005. New tapejarid pterosaur from western Liaoning, china. Acta Geologica Sinica, 79(4): 453-458.

Lü JC, Zhang BK. 2005. New pterodactyloid pterosaur from the Yixian Formation of western Liaoning. Geological Review, 51: 458-462.

Manzig PC, Kellner AWA, Weinschütz LC, Fragoso CE, Vega CS, Guimarães GB, Godoy LC, Liccardo A, Ricetti JHZ, de Moura CC. 2014. Discovery of a rare pterosaur bone bed in a Cretaceous desert with insights on ontogeny and behavior of flying reptiles. PloS one, $9(8)$ : e100005.

Martill DM, Green M, Smith RE, Jacobs ML, Winch J. 2020. First tapejarid pterosaur from the Wessex Formation (Wealden Group: Lower Cretaceous, Barremian) of the United Kingdom. Cretaceous Research, 113: 104487.

Naish D, Witton MP. 2017. Neck biomechanics indicate that giant Transylvanian azhdarchid pterosaurs were short-necked arch predators. PeerJ, 5: e2908.

Naish D, Witton MP, Martin-Silverstone E. 2021. Powered flight in hatchling pterosaurs: evidence from wing form and bone strength. Scientific Reports, 11(1): 1-15. 
657

658

659

660

661

662

663

664

665

666

667

668

669

670

671

672

673

674

675

676

677

678

679

680

681

682

683

Nessov LA. 1984. Pterosaurs and birds of the Late Cretaceous of Central Asia. Paläontologische Zeitschrift, 1: 47-57.

Pan YH, Sha JG, Zhou ZH, Fürsich FT. 2013. The Jehol Biota: definition and distribution of exceptionally preserved relicts of a continental Early Cretaceous ecosystem. Cretaceous Research, 44: 30-38.

Pêgas RV, Leal MEC, Kellner AWA. 2016. A basal tapejarine (Pterosauria; Pterodactyloidea; Tapejaridae) from the crato formation, Early Cretaceous of Brazil. PLoS One, 11(9): e0162692.

Pêgas RV, Holgado B, David LDO, Baiano MA, Costa FR. 2021. On the pterosaur Aerotitan sudamericanus (Neuquén Basin, Upper Cretaceous of Argentina), with comments on azhdarchoid phylogeny and jaw anatomy. Cretaceous Research: 104998.

Vila Nova BC, Sayão JM. 2012. On wing disparity and morphological variation of the Santana Group pterosaurs. Historical Biology, 24(5): 567-574.

Vila Nova BC, Sayão JM, Langer MC, Kellner AWA. 2015. Comments on the cervical vertebrae of the Tapejaridae (Pterosauria, Pterodactyloidea) with description of new specimens. Historical Biology, 27(6): 771-781.

Vullo R, Marugán-Lobónm J, Kellner AWA, Buscalioni A, Fuente M, Moratalla JJ. 2012. A new crested pterosaur from the Early Cretaceous of Spain: The first European tapejarid (Pterodactyloidea: Azhdarchoidea). PLoS ONE, 7: e38900.

Wang L, Li L, Duan Y, Cheng SL. 2006. A new istiodactylid pterosaur from western Liaoning. Geological Bulletin of China, 25: 737-740.

Wang XL, Campos DA, Zhou ZH, Kellner AWA. 2008. A primitive istiodactylid pterosaur (Pterodactyloidea) from the Jiufotang Formation (Early Cretaceous), northeast China. Zootaxa, 1813: 1-18.

Wang XL, Dong ZM. 2008. Order Pterosauria. In: Li JL, Wu XC and Zhang FC (Eds), the Chinese fossil reptiles and their kin, 2nd ed., Beijing: Sci Press, p: 215-234.

Wang XL, Zhou ZH. 2003a. A new pterosaur (Pterodactyloidea, Tapejaridae) from the Early 
684

685

Cretaceous Jiufotang Formation of Western Liaoning, China and its implications for biostratigraphy. Chinese Science Bulletin, 48(1): 16-23.

Wang XL, Zhou ZH. 2003b. Two new pterodactyloid pterosaurs from the Early Cretaceous Jiufotang Formation of Western Liaoning, China. Vertebrata Palasiatica, 41: 34-41.

Wang XL, Zhou ZH. 2006. Pterosaur assemblages of the Jehol Biota and their implication for the Early Cretaceous pterosaur radiation. Geological Journal, 41(3-4): 405-418.

Wang XL, Campos DDA, Zhou ZH, Kellner AWA. 2008. A primitive istiodactylid pterosaur (Pterodactyloidea) from the Jiufotang Formation (Early Cretaceous), northeast China.

Wellnhofer P. 1978. Handbuch der Paläoherpetologie. Teil 19: Pterosauria. Stuttgart, Gustav Fischer Verlag.

Wellnhofer P. 1987. New crested pterosaurs from the Lower Cretaceous of Brazil. Mitteilungen der Bayerischen Staatssammlung für Paläontologie und historische Geologie, 27: 175186.

Wilson JA. 2006. Anatomical nomenclature of fossil vertebrates: standardized terms or 'lingua franca'? Journal of Vertebrate Paleontology, 26(3): 511-518.

Witton MP. 2013. Pterosaurs. Princeton University Press.

Witton MP, Martill DM, Green M. 2009. On pterodactyloid diversity in the British Wealden (Lower Cretaceous) and a reappraisal of "Palaeornis" cliftii Mantell, 1844. Cretaceous Research, 30: 676-686.

Wu WH, Zhou CF, Andres B. 2017. The toothless pterosaur Jidapterus edentus (Pterodactyloidea: Azhdarchoidea) from the Early Cretaceous Jehol Biota and its paleoecological implications. PLoS One, 12(9): e0185486.

Xu X, Zhou ZH, Wang XL, Kuang XW, Zhang FC, Du XK. 2003. Four-winged dinosaurs from China. Nature, 421(6921): 335-340.

Xu X, Zhou ZH, Wang Y, Wang M. 2020. Study on the Jehol Biota: recent advances and future prospects. Science China Earth Sciences, 63(6): 757-773.

Zhang FC, Zhou ZH, Hou LH, Gu G. 2001. Early diversification of birds: evidence from a 
711

712

713

714

715

716

717

718

719

720

721

722

723

724

725

726

727

728

729

730

731

732

733

734

735

736

737

738

new opposite bird. Chinese Science Bulletin, 46(11): 945-949

Zhang XJ, Jiang SX, Cheng X, Wang XL. 2019. New material of Sinopterus (Pterosauria, Tapejaridae) from the Early Cretaceous Jehol Biota of China. Anais da Academia Brasileira de Ciências, 91.

Zhou CF. 2010. New material of Chaoyangopterus (Pterosauria: Pterodactyloidea) from the Early Cretaceous Jiufotang Formation of western Liaoning, China. Neues Jahrbuch fur Geologie und Palaontologie-Abhandlungen, 257(3): 341.

Zhou XY, Pêgas RV, Leal MEC, Bonde N. 2019. Nurhachius luei, a new istiodactylid pterosaur (Pterosauria, Pterodactyloidea) from the Early Cretaceous Jiufotang Formation of Chaoyang City, Liaoning Province (China) and comments on the Istiodactylidae. PeerJ, 7: e7688.

Zhou ZH, Clarke J, Zhang FC, Wings O. 2004. Gastroliths in Yanornis: an indication of the earliest radical diet-switching and gizzard plasticity in the lineage leading to living birds? Naturwissenschaften, 91(12): 571-574.

Zhou ZH, Zhang FC. 2002a. Largest bird from the Early Cretaceous and its implications for the earliest avian ecological diversification. Naturwissenschaften, 89: 34-38.

Zhou ZH, Zhang FC. 2002b. A long-tailed, seed-eating bird from the Early Cretaceous of China. Nature, 418: 405-409.

Zhou ZH, Zhang FC. 2003. Jeholornis compared to Archaeopteryx, with a new understanding of the earliest avian evolution. Naturwissenschaften, 90: 220-225.

\section{Figures}

Figure 1. Specimen D3072, general view. (A) Photograph and (B) schematic drawing. Abbreviations: cv, cervical vertebrae; co, coracoid; dv, dorsal vertebrae; dr, dorsal rib; fi, fíbula; h, humerus; mc, metacarpal; mt, metatarsal; pt, pteroid; ra, radius; sc, scapula; ti, tibia; ul, ulna; wph, wing phanlanx.

Figure 2. Specimen D3072, mid-cervical vertebrae. (A) Photograph and (B) schematic 
739

drawing. Abbreviations: c, cervical; hyp, hypapophysis; pf, pneumatic foramen; poex, postexapophysis; poz, postzygapophysis; prz, prezygapophysis. Scale bar equals $10 \mathrm{~mm}$.

Figure 3. Specimen D3072, trunk region. (A) Photograph and (B) schematic drawing. Abbreviations: c, cervical; co, coracoid; d, dorsal; h, humerus; r, rib; sc, scapula.

Figure 4. Specimen D3072, humerus. Photograph of (A) left and (B) right humeri. Schematic drawing of (A) left and (B) right humeri. Abbreviations: dpc, deltopectoral crest; $h$, head; pf, pneumatic foramen; uc, ulnar crest. Scale bar equals $10 \mathrm{~mm}$.

Figure 5. Specimen D3072, radius and ulna. Proximal region, (A) photograph and (B) schematic drawing. Scale bar equals $10 \mathrm{~mm}$. Distal region, (C) photograph and (D) schematic drawing. Abbreviations: ca, carpal; capc, capitular cotyle; ctb, crest for M. triceps brachii; dclp, dorsal collateral process; epi, epiphysis; h, humerus; ol, olecranon; pt, pteroid; ra, radius; troc, trochlear cotyle; ul, ulna; vclp, ventral colateral process.

Figure 6. Specimen D3072, right carpus and manus. (A) Photograph and (B) schematic drawing. Abbreviations: d, digit; dc, distal carpals; etp, extensor tendon process; lpc, lateral proximal carpal; mc, metacarpal; mpc, medial proximal carpal; pt, pteroid; ra, radius; ul, ulna; pc, preaxial carpal; pf, pneumatic foramen; ph, phanlanx; pt, pteroid. Scale bar equals $10 \mathrm{~mm}$.

Figure 7. Specimen D3072, pedes. Right pes, (A) photograph and (B) schematic drawing. Left pes, (C) photograph and (D) schematic drawing. Abbreviations: f, fibula; ldt, lateral distal tarsal; lpt, lateral proximal tarsal; mdt, medial distal tarsal; mt, metatarsal; t, tibia; us, ungual sheath. Scale bar equals $10 \mathrm{~mm}$.

Figure 8. Wing elements proportions (in percentage of total wing length) in selected azhdarchoids. Data source: Sinopterus dongi (holotype, IVPP V 13363; Wang \& Zhou (2003a); Sinopterus "jii" (holotype, GMN-03-11-001; Lü \& Yuan, 2005); S. atavismus (holotype, XHPM 1009; Lü et al., 2016); Eopteranodon lii (D2526, Lü et al., 2006b); D2525 (Lü et al., 2006c); 
770 "Huaxiapterus" benxiensis (holotype, BXGM V0011; Lü et al., 2007); "Huaxiapterus" 771 corollatus (holotype, ZMNH M8131), Lü et al. (2006a); Tupandactylus navigans (GP/2E 9266), 772 Beccari et al. (2021); Caiuajara dobruskii (composite), Manzig et al. (2014); Jidapterus edentus 773 (holotype, RCPS-030366CY), Wu et al. (2017); Chaoyangopterus zhangi (holotype, IVPP V 774 13397), Wang \& Zhou (2003b); Shenzhoupterus chaoyangensis (holotype, HGM 41HIII-305A), 775 Lü et al. (2008). Abbreviations: d, digit; hol., holotype; McIV, metacarpal IV; ph, phalanx.

Figure 9. Humerus morphology in tapejarines. (A) Caupedactylus ybaka, right humerus in anterior view, drawn from Kellner (2013). (B) D3072, left humerus in an approximately ventral view. (C) Tupandactylus navigans, mirrored right humerus in posterior view, drawn from Beccari et al. (2021). (D) Caiuajara dobruskii, mirrored left humerus in anterior view, drawn from Manzig et al. (2014). (E) Tapejara wellnhoferi, right humerus in anterior view, drawn from Eck et al. (2011). Notice the variation in the orientation of the deltopectoral crest, perpendicular to humeral shaft in (A) and (B), and oblique in (C), (D) and (E). Scale bars equal $10 \mathrm{~mm}$.

\section{Tables}

Table 1. Measurements of the new specimen D3072. Measurements given in milimeters. 


\section{Figure 1}

Figure 1. Specimen D3072, general view.

(A) Photograph and (B) schematic drawing. Abbreviations: cv, cervical vertebrae; co, coracoid; dv, dorsal vertebrae; dr, dorsal rib; fi, fíbula; h, humerus; mc, metacarpal; mt, metatarsal; pt, pteroid; ra, radius; sc, scapula; ti, tibia; ul, ulna; wph, wing phanlanx. 

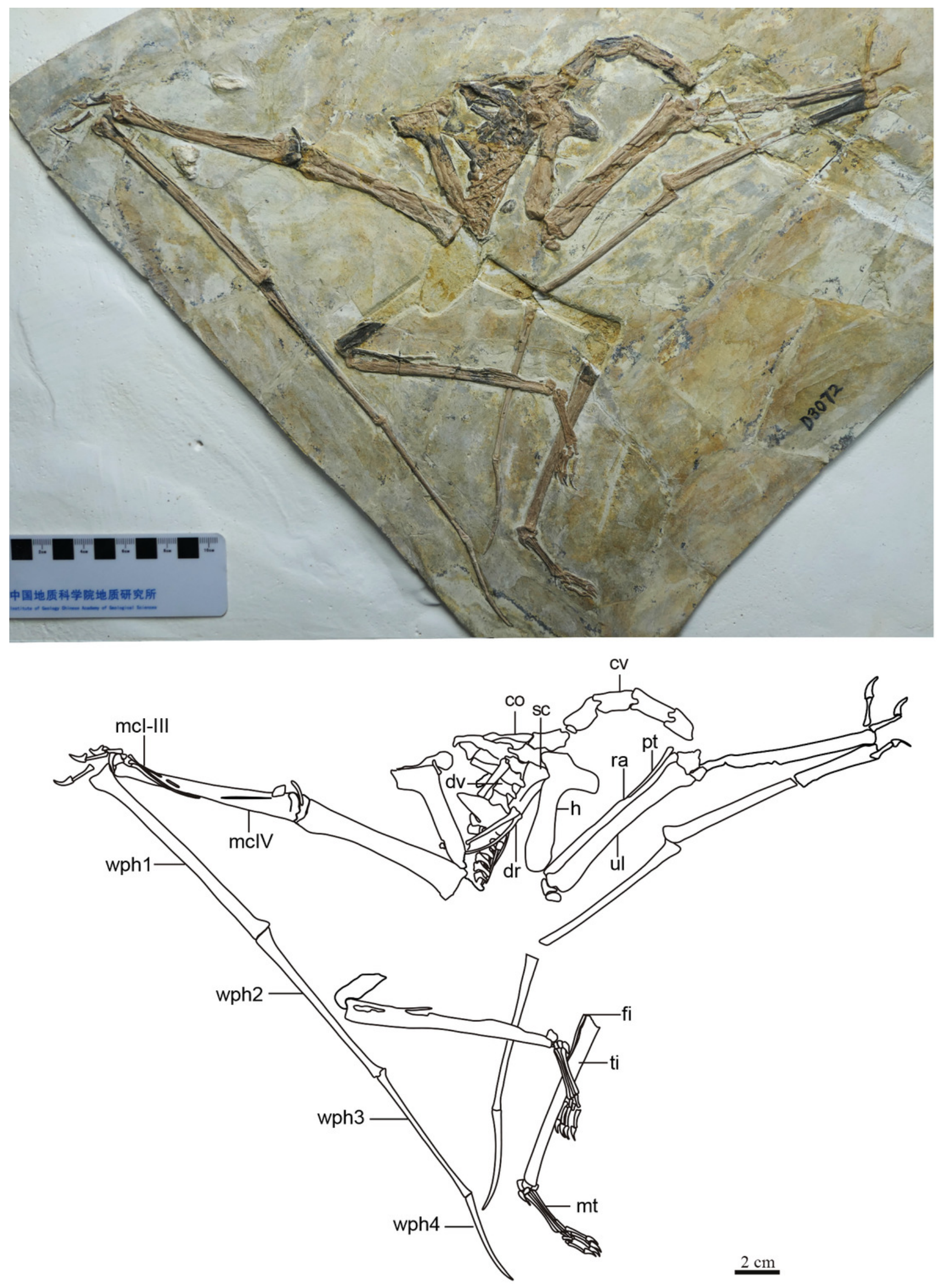
Figure 2

Figure 2. Specimen D3072, mid-cervical vertebrae.

(A) Photograph and (B) schematic drawing. Abbreviations: c, cervical; hyp, hypapophysis; pf, pneumatic foramen; poex, postexapophysis; poz, postzygapophysis; prz, prezygapophysis. Scale bar equals $10 \mathrm{~mm}$. 


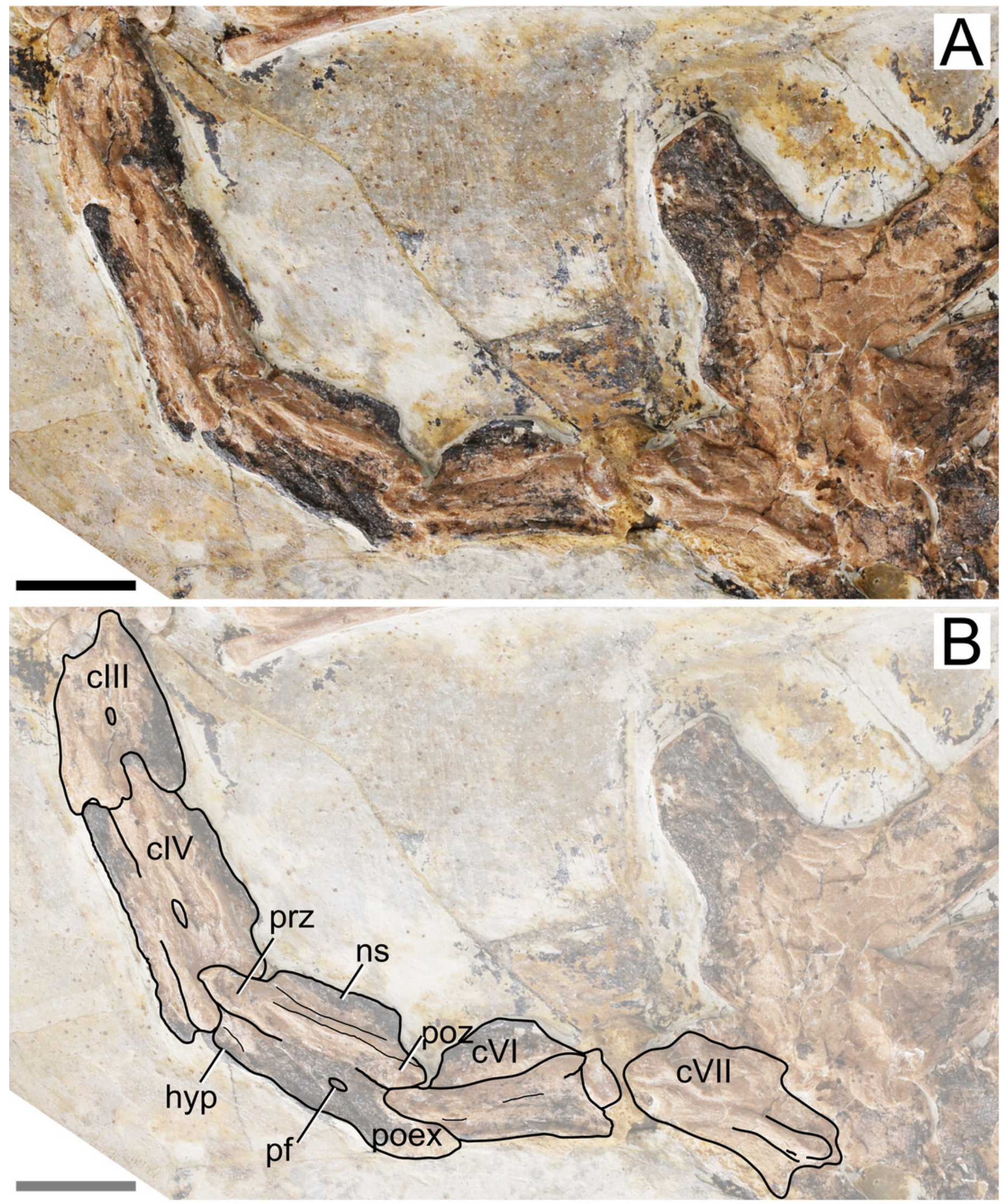


Figure 3

Figure 3. Specimen D3072, trunk region.

(A) Photograph and (B) schematic drawing. Abbreviations: c, cervical; co, coracoid; d, dorsal; h, humerus; r, rib; sc, scapula.
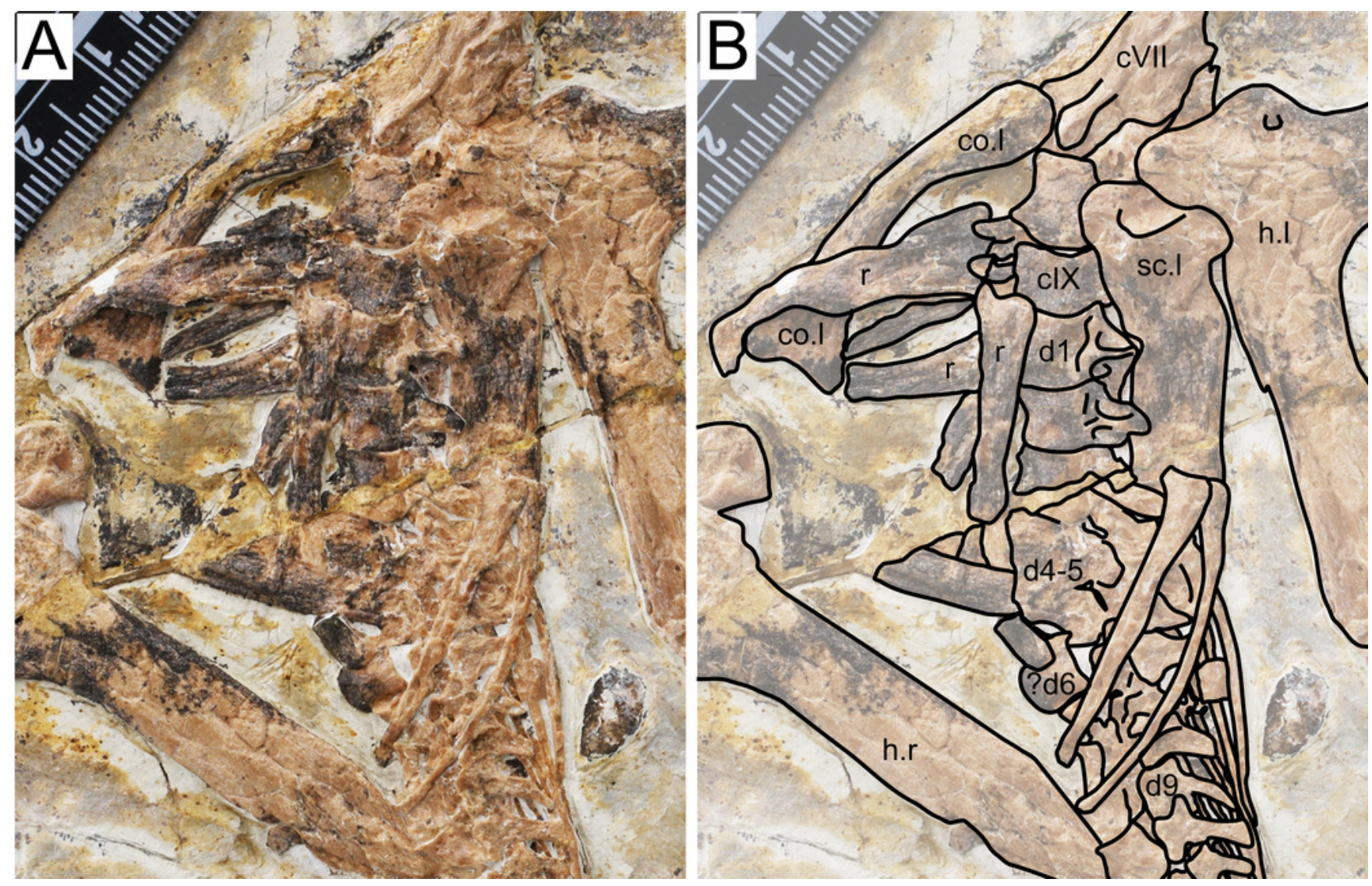
Figure 4

Figure 4. Specimen D3072, humerus.

Photograph of (A) left and (B) right humeri. Schematic drawing of (A) left and (B) right humeri. Abbreviations: dpc, deltopectoral crest; $h$, head; pf, pneumatic foramen; uc, ulnar crest. Scale bar equals $10 \mathrm{~mm}$. 

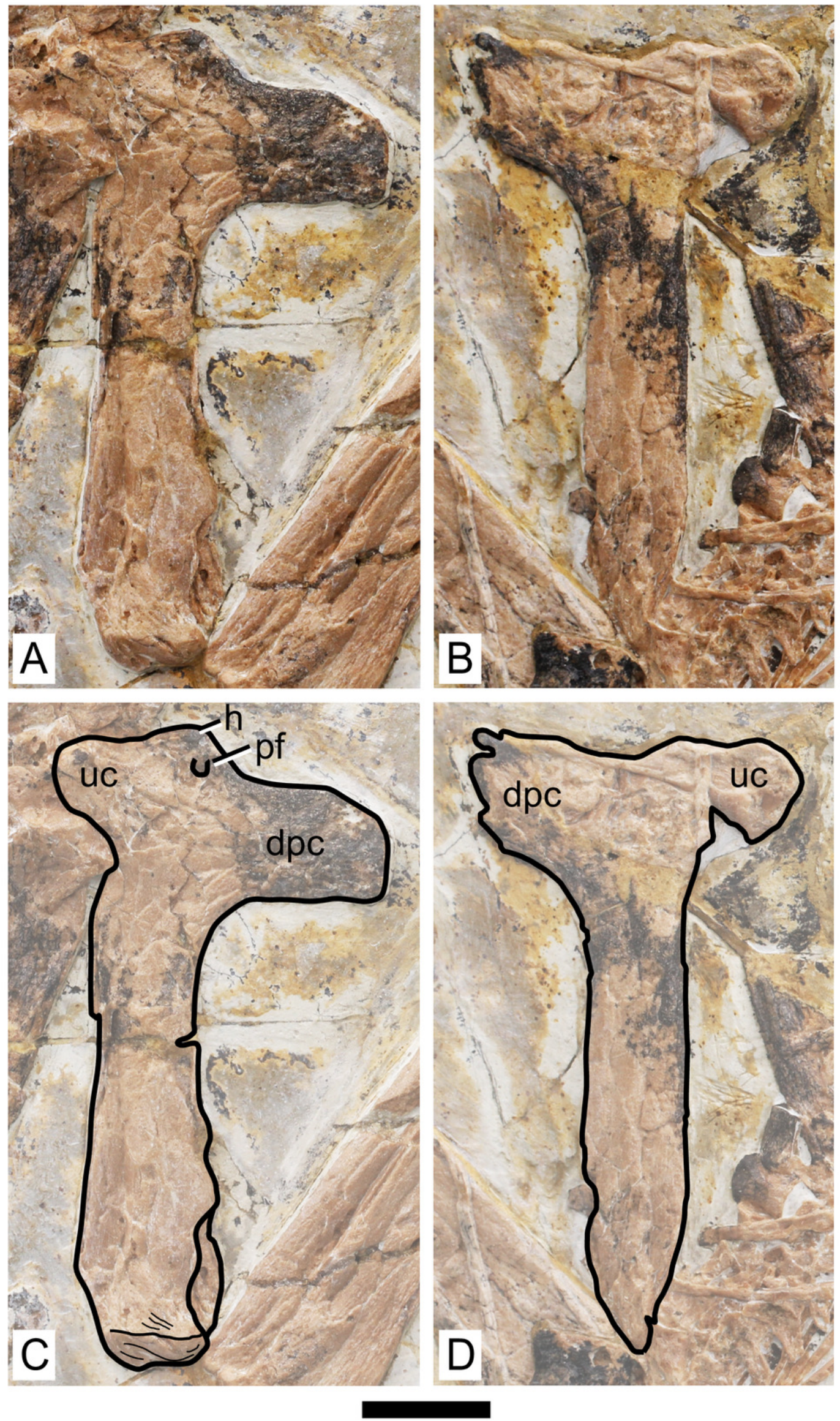


\section{Figure 5}

Figure 5. Specimen D3072, radius and ulna.

Proximal region, (A) photograph and (B) schematic drawing. Scale bar equals $10 \mathrm{~mm}$. Distal region, (A) photograph and (B) schematic drawing. Abbreviations: ca, carpal; capc, capitular cotyle; ctb, crest for M. triceps brachii; dclp, dorsal collateral process; epi, epiphysis; h, humerus; ol, olecranon; pt, pteroid; ra, radius; troc, trochlear cotyle; ul, ulna; vclp, ventral colateral process. 

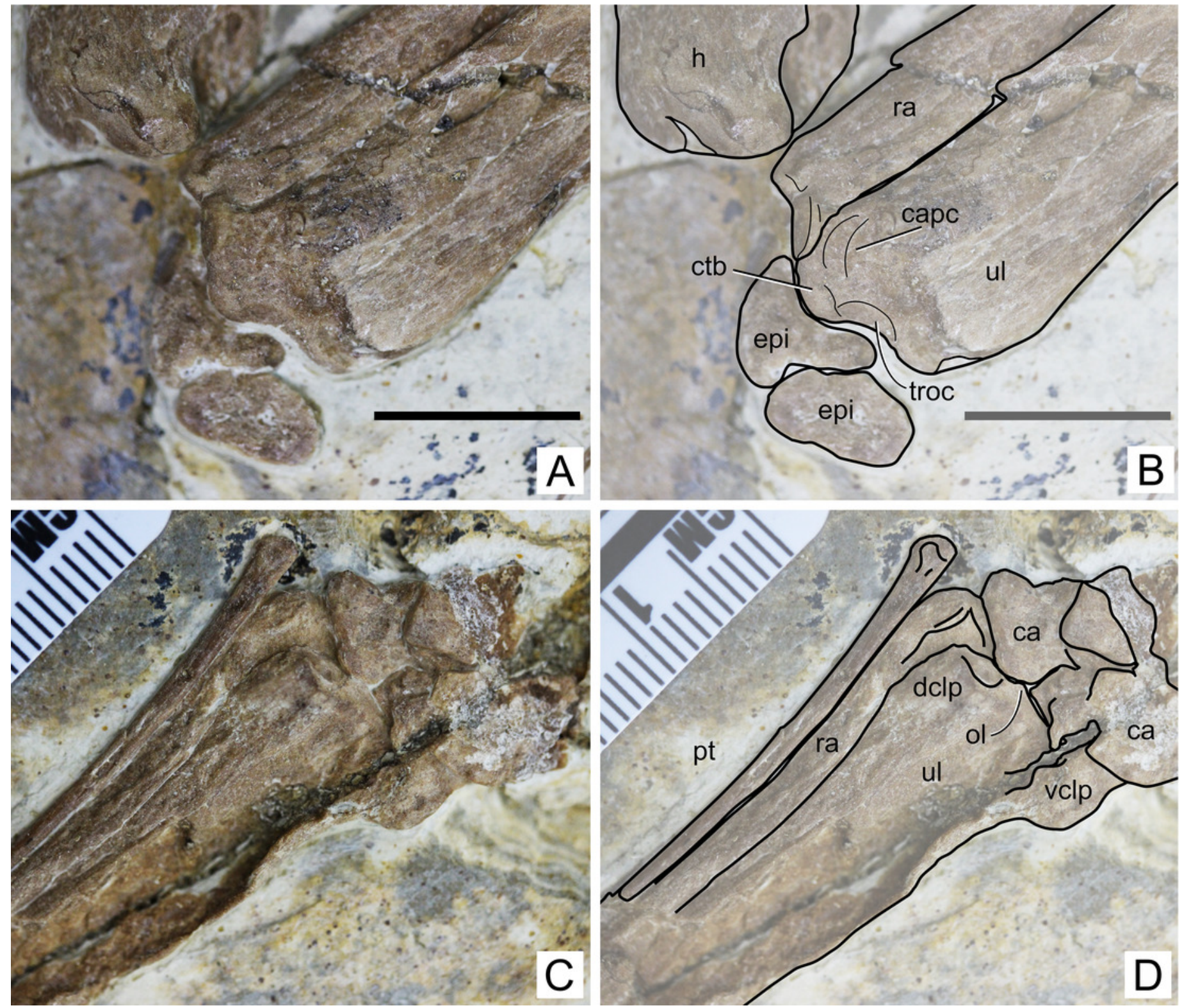
Figure 6

Figure 6. Specimen D3072, right carpus and manus.

(A) Photograph and (B) schematic drawing. Abbreviations: d, digit; dc, distal carpals; etp, extensor tendon process; Ipc, lateral proximal carpal; mc, metacarpal; mpc, medial proximal carpal; pt, pteroid; ra, radius; ul, ulna; pc, preaxial carpal; pf, pneumatic foramen; ph, phanlanx; pt, pteroid. Scale bar equals $10 \mathrm{~mm}$.

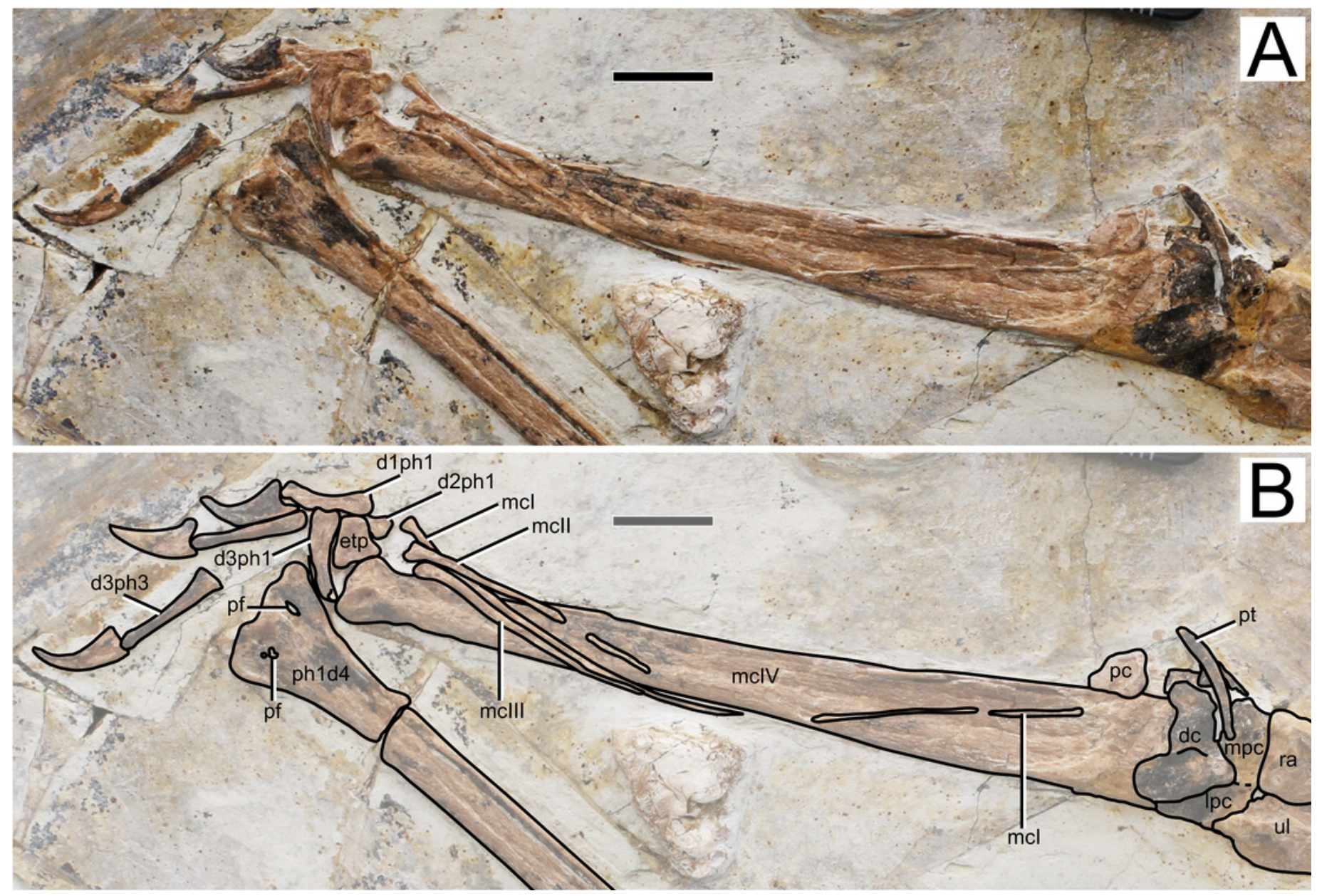




\section{Figure 7}

Figure 7. Specimen D3072, pedes.

Right pes, (A) photograph and (B) schematic drawing. Left pes, (C) photograph and (D) schematic drawing. Abbreviations: f, fibula; Idt, lateral distal tarsal; Ipt, lateral proximal tarsal; mdt, medial distal tarsal; mt, metatarsal; t, tibia; us, ungual sheath. Scale bar equals $10 \mathrm{~mm}$. 

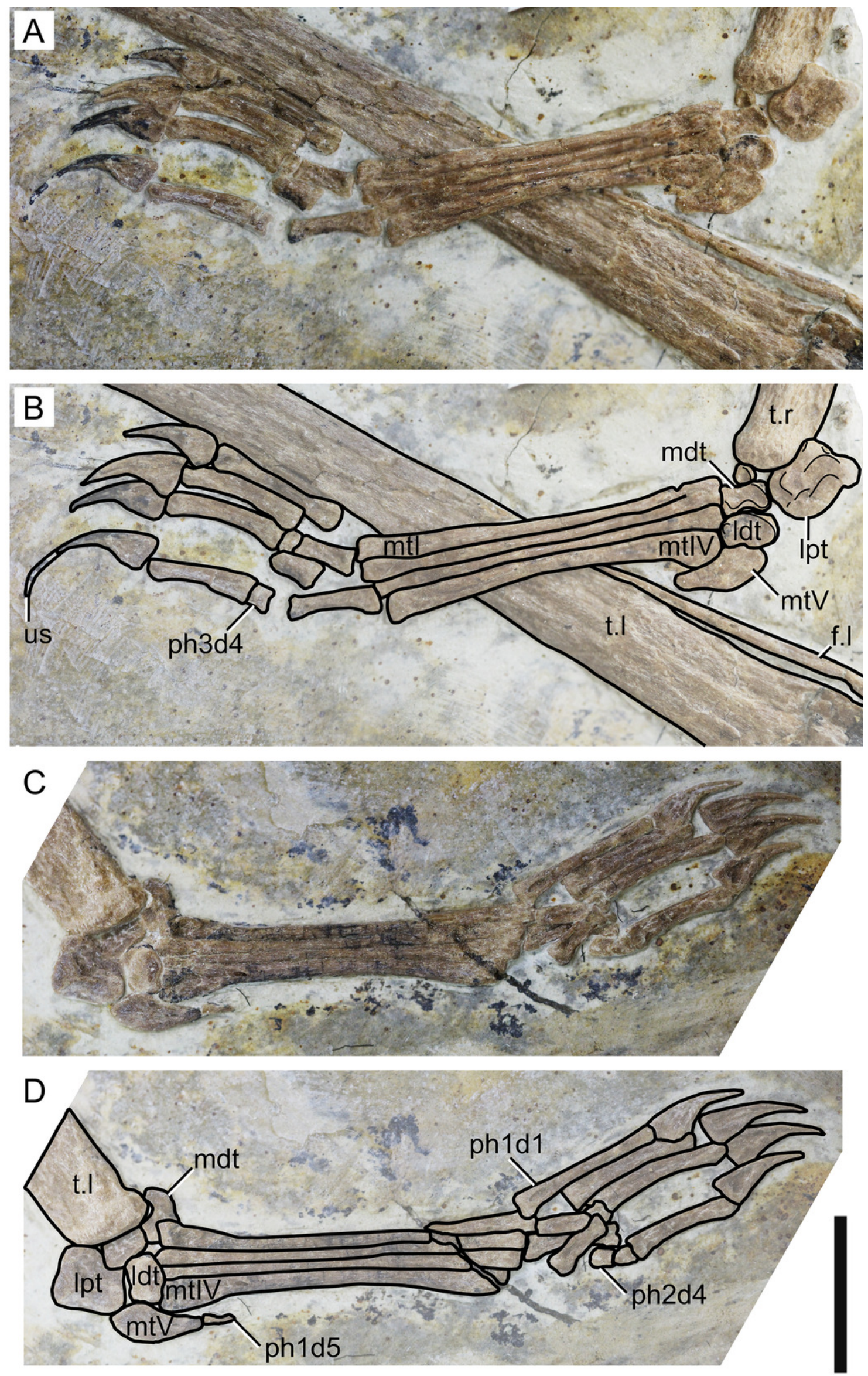


\section{Figure 8}

Figure 8. Wing elements proportions (in percentage of total wing length) in selected azhdarchoids.

Data source: Sinopterus dongi (holotype, IVPP V 13363; Wang \& Zhou (2003a); Sinopterus "jii" (holotype, GMN-03-11-001; Lü \& Yuan, 2005); S. atavismus (holotype, XHPM 1009; Lü et al., 2016); Eopteranodon lii (D2526, Lü et al., 2006b); D2525 (Lü et al., 2006c); "Huaxiapterus" benxiensis (holotype, BXGM V0011; Lü et al., 2007); "Huaxiapterus" corollatus (holotype, ZMNH M8131), Lü et al. (2006a); Tupandactylus navigans (GP/2E 9266), Beccari et al. (2021); Caiuajara dobruskii (composite), Manzig et al. (2014); Jidapterus edentus (holotype, RCPS-030366CY), Wu et al. (2017); Chaoyangopterus zhangi (holotype, IVPP V 13397), Wang \& Zhou (2003b); Shenzhoupterus chaoyangensis (holotype, HGM 41HIII-305A), Lü et al. (2008). Abbreviations: d, digit; hol., holotype; McIV, metacarpal IV; ph, phalanx.

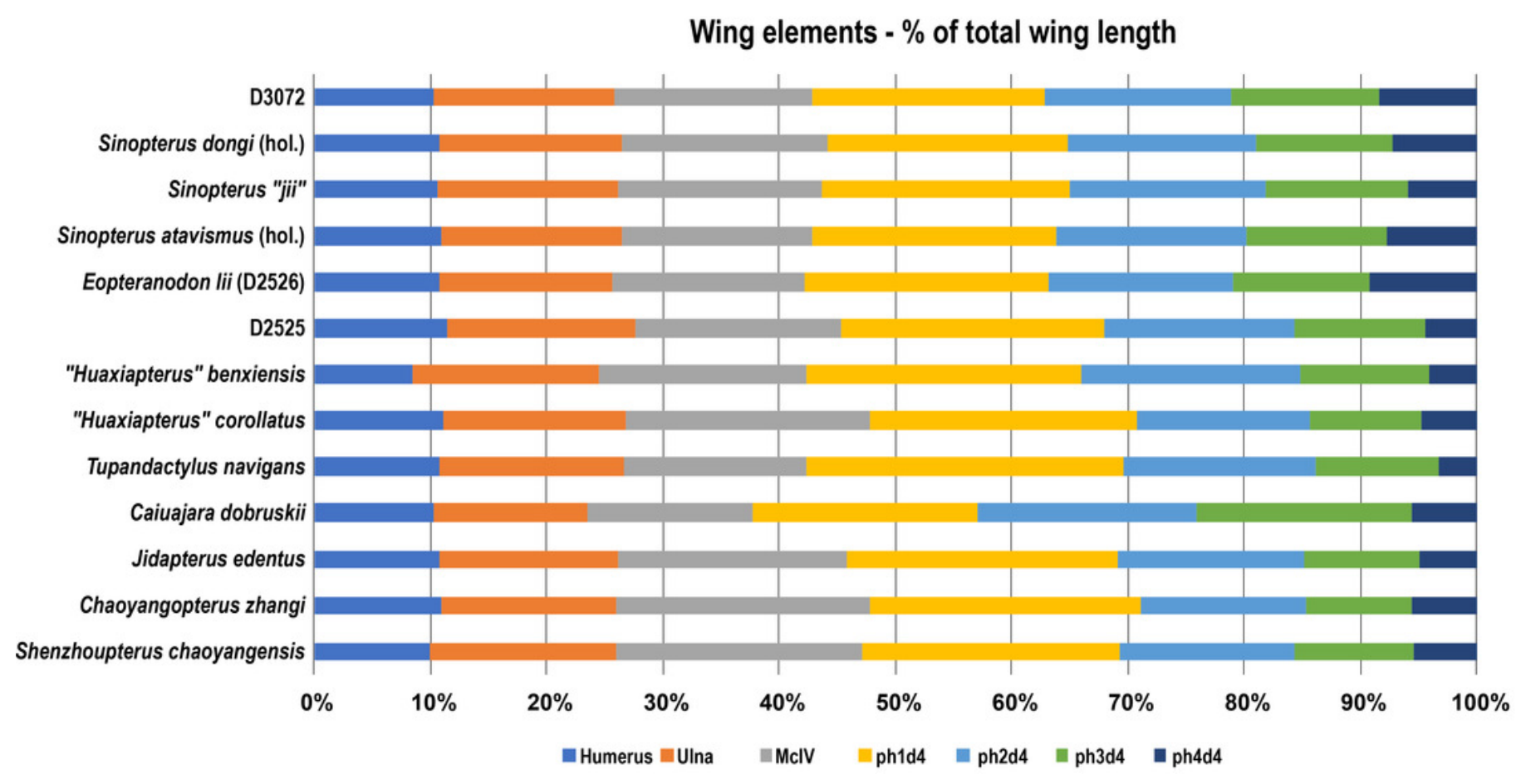


Figure 9

Figure 9. Humerus morphology in tapejarines.

(A) Caupedactylus ybaka, right humerus in anterior view, drawn from Kellner (2013). (B) D3072, left humerus in an approximately ventral view. (C) Tupandactylus navigans, mirrored right humerus in posterior view, drawn from Beccari et al. (2021). (D) Caiuajara dobruskii, mirrored left humerus in anterior view, drawn from Manzig et al. (2014). (E) Tapejara wellnhoferi, right humerus in anterior view, drawn from Eck et al. (2011). Notice the variation in the orientation of the deltopectoral crest, perpendicular to humeral shaft in (A) and (B), and oblique in (C), (D) and (E). Scale bars equal $10 \mathrm{~mm}$.
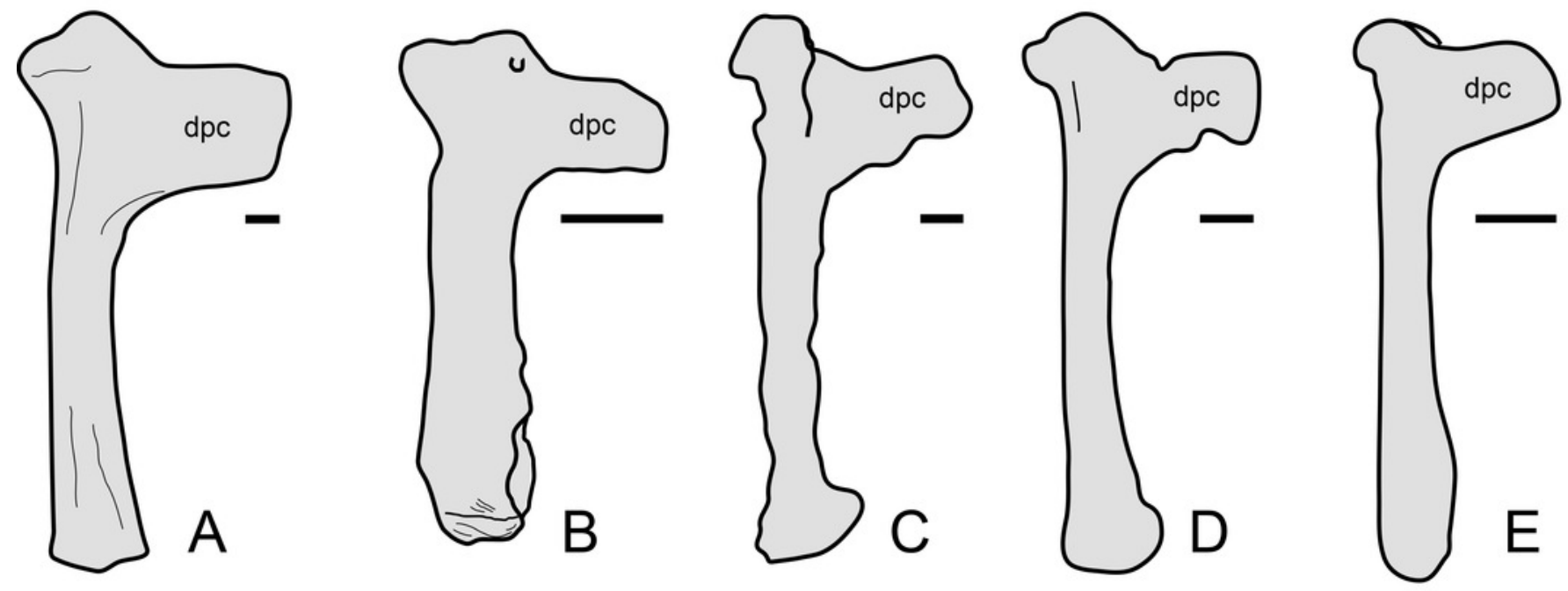


\section{Table 1 (on next page)}

Table 1. Measurements of limb elements in the new specimen D3072. 


\begin{tabular}{|c|c|c|}
\hline Elements & length & width \\
\hline Cervicals 3-7 & $12.4 / 22.5 / 19.0 / 17.4 / 15.5$ & $\begin{array}{l}8.3 / 9.1 / 9.6 / 8.6 / 10.2 \\
\text { (height) }\end{array}$ \\
\hline Dorsal series & 66.7 (preserved) & $?$ \\
\hline Coracoid & 32.8 (preserved) & 5 (shaft) \\
\hline Humerus (1.) & 55.1 & 9.1 (shaft) \\
\hline Deltopectoral crest (1.) & 14.1 & 10.5 \\
\hline Ulna/radius (1.) & $82.6 / 82.6$ & $8.2 / ?$ \\
\hline Pteroid (1.) & 32.0 (preserved) & - \\
\hline Metacarpals I-III (r.) & $88.5 / 34.2 / 33.3$ & $\sim 1$ (midshaft) \\
\hline Metacarpal IV (r.) & 90.8 & 8.6 \\
\hline $\begin{array}{l}\text { Manual digit } 1 \text { (r.), } \\
\text { phalanges } 1-2\end{array}$ & $11.8 / 12.5$ & $\begin{array}{l}\sim 2 \quad(\text { midshaft }) / 5.1 \\
\text { (dorsoventral) }\end{array}$ \\
\hline $\begin{array}{l}\text { Manual digit } 2 \text { (r.), } \\
\text { phalanges } 1-3\end{array}$ & $? / 14.9 / 11.3$ & $\begin{array}{l}? / \sim 2 \quad \text { (midshaft)/5 } \\
\text { (dorsoventral) }\end{array}$ \\
\hline $\begin{array}{l}\text { Manual digit } 3 \text { (r.), } \\
\text { phalanges } 1-4\end{array}$ & $22.0 / ? / 14.5 / 12.1$ & $\begin{array}{l}\sim 1.5 \quad \text { (midshaft)/?/ 1.5 } \\
(\text { midshaft) } / 4.6 \\
\text { (dorsoventral) }\end{array}$ \\
\hline Wing phalanx 1 & 107.7 (r.), 108.6 (1.) & 5.8 (r.), $5.9(1)$. \\
\hline Wing phalanx 2 & $85.6(\mathrm{r})$. & 4.1 (r.), 4.2 (1.) \\
\hline Wing phalanx 3 & $67.8(\mathrm{r})$. & 2.2 (r.), $2.3(1)$. \\
\hline
\end{tabular}




\begin{tabular}{lll} 
Wing phalanx 4 & $45.0($ r. $), 46.5(1)$. & $1.8($ r. $), 1.9(1)$. \\
\hline Tibia (r.) & 97.7 & $8.58($ shaft $)$ \\
\hline Metatarsals I-IV & $23.7 / 23.0 / 22.6 / 21.5(1)$. & $1.0 / 0.8 / 0.7 / 1.2($ r. $)$ \\
& $24.9 / 23.6 / 23.1 / 22.1$ (r.) & $1.1 / 0.9 / 0.8 / 1.2(1)$.
\end{tabular}

4 Table 1. Measurements of the new specimen D3072. Measurements given in milimeters. 5 